\title{
Additions to the genus Cytospora with sexual morph in Cytosporaceae
}

\section{Shang $\mathbf{Q J}^{1,2,3}$, Hyde $\mathbf{K D}^{3,4}$, Camporesi $\mathbf{E}^{5}$, Maharachchikumbura $\mathrm{SSN}^{1}$, Norphanphoun $\mathrm{C}^{3,4}$, Brooks $\mathrm{S}^{4}$, Liu $\mathrm{JK}^{1^{*, 2}}$}

\author{
${ }^{1}$ School of Life Science and Technology, University of Electronic Science and Technology of China, Chengdu 611731, \\ P.R. China \\ ${ }^{2}$ Guizhou Key Laboratory of Agricultural Biotechnology, Guizhou Academy of Agricultural Sciences, Guiyang 550006, \\ P.R. China \\ ${ }^{3}$ Centre of Excellence in Fungal Research, Mae Fah Luang University, Chiang Rai 57100, Thailand \\ ${ }^{4}$ School of Science, Mae Fah Luang University, Chiang Rai 57100, Thailand \\ ${ }^{5}$ A.M.B. Gruppo Micologico Forlivese, Antonio Cicognani, Via Roma 18, Forlì, Italy
}

Shang QJ, Hyde KD, Camporesi E, Maharachchikumbura SSN, Norphanphoun C, Brooks S, Liu JK 2020 - Additions to the genus Cytospora with sexual morph in Cytosporaceae. Mycosphere 11(1), 189-224, Doi 10.5943/mycosphere/11/1/2

\begin{abstract}
Cytospora species are important pathogens, which have a worldwide distribution, broad host range and are commonly associated with tree dieback and canker disease. Lack of ex-type cultures or inability to link multi-gene DNA sequence data in GenBank to phylogenetic analyses makes it difficult to classify Cytospora taxa to species level. In this study, ten specimens of Cytospora were collected from dead wood in China, Italy and Thailand. Based on their morphology and phylogenetic characterization, four new species (C. diopuiensis, C. galegicola, C. pingbianensis and C. pubescentis) and four known species (C. cedri, C. cotini, C. predappioensis and C. prunicola) are herein described, illustrated and compared with related taxa. Detailed morphological descriptions of the holomorph (C. galegicola, C. prunicola, C. predappioensis and C. pubescentis), the sexual morph (C. cedri, C. cotini, C. diopuiensis and C. pingbianensis) and a new record of $C$. predappioensis in China are provided. Phylogenetic analyses of a combined ITS, LSU, ACT and RPB2 DNA sequence dataset support their placement in the genus Cytospora and justify the new species and identification of known species.
\end{abstract}

Key words - 4 new taxa - Diaporthales - Multi-gene - phylogeny - taxonomy

\section{Introduction}

Cytospora (Cytosporaceae, Diaporthales, Sordariomycetes, Ascomycota) was established by Ehrenberg (1818) with Cytospora chrysosperma (Pers.) Fr. as the type species. Cytospora species are important phytopathogens, causing dieback and canker disease on a broad range of plants worldwide (Adams et al. 2005, 2006, Lawrence et al. 2018, Fan et al. 2020). It leads to commercial losses, such as reduction of economically important fruits and nut crops on Juglandaceae spp., Punicaceae spp., Rosaceae spp. and Rhamnaceae spp. (Wang et al. 2011, Du et al. 2013, Fan et al. 2015a, b, 2020, Palavouzis et al. 2015, Lawrence et al. 2018, Pan et al. 2018, Zhu et al. 2018). Species of Cytospora also result in ecological damage, for example, the destructive canker diseases of the anti-desertification plants on Elaeagnaceae spp. and Salicaceae spp. (Fan et al. 2015b). Members of Cytospora are also recognized as endophytes and saprobes, and commonly connected 
with a wide range of hosts worldwide (Christensen 1940, Spielman 1983, Bills 1996). There are 647 epithets of Cytospora listed in Index Fungorum (November, 2019) and 110 estimated species in Kirk et al. (2008). The Cytospora species are characterized by the single or labyrinthine, loculate stromata, filamentous conidiophores or asci, and allantoid hyaline conidia or ascospores (Spielman 1983, 1985, Adams et al. 2005, Fan et al. 2015a, b, Norphanphoun et al. 2017). Recent studies have been carried out and dealt with the taxonomy of Cytospora species based on multi-gene analysis of combined ITS, LSU, ACT, RPB2, TEF and TUB2 sequence data (Fan et al. 2014a, b, 2015a, b, 2020, Yang et al. 2015, Lawrence et al. 2017, 2018, Norphanphoun et al. 2017, 2018, Pan et al. 2018, Zhu et al. 2018).

The sexual morphs of Cytospora species are reported as Leucocytospora, Leucostoma, Valsa, Valsella, and Valseutypella (Fries 1823, Saccardo 1884, Kobayashi 1970, Barr 1978, Gvritishvili 1982, Spielman 1983, 1985, Adams et al. 2002, 2005, Castlebury et al. 2002, Bulgakov 2010, Maharachchikumbura et al. 2015, 2016, Rossman et al. 2015, Yang et al. 2015, Hyde et al. 2016, Li et al. 2016, Norphanphoun et al. 2017, 2018, Zhu et al. 2018). Combining the morphological studies from several decades with the phylogenetic results of DNA sequence data, Adams et al. (2005) revised the genus Cytospora and synonymized all the sexual genera under Valsa, either as subgenera or species without additional infrageneric rank (von Höhnel 1906, 1914, 1917, 1919, 1928, von Petrak 1919, 1969, Défago 1942, Urban 1957, Hubbes 1960, Barr 1978, 1990, Vasilyeva 1988, 1994, Adams et al. 2005). Following the International Code of Nomenclature for Algae, Fungi, and Plants (McNeill et al. 2012), which permits the single-name for pleomorphic taxa, Cytospora (1818) was treated as the recommended name instead of Valsa (1849) as it is older and more widely used (Adams et al. 2005, Rossman et al. 2015).

The sexual morph of Cytospora is rarely found in nature (Saccardo 1884, 1986, Sydow et al. 1916, Adams et al. 2005, Norphanphoun et al. 2017). In the asexual morph however, formal descriptions for some species of Cytospora (e.g., C. coenobitica and C. rhodophila) only provided details on conidial sizes (Saccardo 1884). Moreover, there is only ITS rDNA sequence data available for most Cytospora species in GenBank, and this makes it difficult to classify Cytospora, especially to species level. Adams et al. (2005) suggested that extensive fresh collections, especially with neotypes or epitypes, should be made and their molecular data obtained to clarify taxonomy of Cytospora.

The aim of this study is to provide more evidence to justify and stabilize the taxonomic identification of Cytospora species. Ten Cytospora specimens with their sexual morphs were collected from dead branches in China, Italy and Thailand. All specimens were characterized by multi-loculate, conspicuous stromata, perithecial ascomata, 8-spored, unitunicate asci and hyaline, allantoid, aseptate ascospores. Based on the morphological comparison and phylogenetic analyses, four new species are introduced, four known species are identified and detailed descriptions and illustrations are provided. The holomorphs of C. galegicola, C. prunicola, C. predappioensis and C. pubescentis are provided from fresh specimens and pure cultures. In addition, Cytospora predappioensis is reported as a new record in China. A phylogenetic tree based on a combined ITS, LSU, ACT and RPB2 sequence analysis is provided.

\section{Materials and Methods}

\section{Isolation and morphology}

Dead wood samples were collected from Yunnan Province, China, Forlì-Cesena Province, Italy and Chiang Mai Province, Thailand. The samples were taken back to the laboratory in plastic ziplock bags and maintained at room temperature. The specimens were examined following the methods described in Dai et al. (2017). Macro-morphological characters were examined using a Motic SMZ-140 dissecting microscope and photographed using a Carl Zeiss GmbH (AxioCam ERc 5s) stereo microscope. A Canon EOS 600D camera connected to a Nikon Eclipse 80i compound microscope was used to examine and capture the fungal micro-morphology. Fungal structures were measured using the Tarosoft (R) Image Frame Work software (Version 0.9.7) (Liu et al. 2010). 
Pure cultures were obtained by single spore isolation as described in Chomnunti et al. (2014) and deposited in Mae Fah Luang University Culture Collection (MFLUCC) and Kunming Culture Collection (KUMCC). Herbarium materials were deposited in the herbarium of Mae Fah Luang University (MFLU) and duplicated in the herbarium of Cryptogams Kunming Institute of Botany Academia Sinica (KUN-HKAS). Faces of Fungi and Index Fungorum numbers are registered following the outline of Jayasiri et al. (2015) and Index Fungorum (2019), respectively. New taxa are established based on recommendations as outlined by Jeewon \& Hyde (2016).

\section{DNA extraction, PCR amplification and sequencing}

Total genomic DNA was extracted from fresh fungal mycelium scraped from the margin of a colony grown on potato dextrose agar (PDA) for 1-4 weeks (which incubated at $16^{\circ} \mathrm{C}$ for Italy specimens, $25^{\circ} \mathrm{C}$ for specimens from China and $30^{\circ} \mathrm{C}$ for specimens from Thailand) by using a DNA extraction kit (Biospin Fungus Genomic DNA Extraction Kit, BioFlux®, China) following the protocols in the manufacturer's instructions.

The DNA amplification was performed through polymerase chain reaction (PCR), following details as below. The internal transcribed spacers (ITS), large subunit rDNA (LSU), $\alpha$-actin (ACT) and RNA polymerase II largest subunit (RPB2) gene regions were amplified using the primer pairs ITS4 with ITS5 (White et al. 1990), LR0R with LR5 (Vilgalys \& Hester 1990), ACT512F with ACT783R (Carbone \& Kohn 1999) and RPB2-5F with fRPB2-7cR (Liu et al. 1999), respectively. The PCR thermal cycle profile for the ITS, LSU and ACT regions were; initially at $94^{\circ} \mathrm{C}$ for 3 minutes, followed by 35 cycles of denaturation at $94^{\circ} \mathrm{C}$ for 30 seconds, annealing at $55^{\circ} \mathrm{C}$ for 1 minute, elongation at $72^{\circ} \mathrm{C}$ for 90 seconds and a final extension at $72^{\circ} \mathrm{C}$ for 10 minutes. PCR profile for the RPB2 locus was as follows: initially at $95^{\circ} \mathrm{C}$ for 5 minutes, followed by 35 cycles of denaturation at $94^{\circ} \mathrm{C}$ for 1 minute, annealing at $52^{\circ} \mathrm{C}$ for 1 minute, elongation at $72^{\circ} \mathrm{C}$ for 90 seconds, and a final extension at $72^{\circ} \mathrm{C}$ for 10 minutes. Purification and sequencing of the PCR products with the same PCR primers mentioned above were carried out at Shanghai Sangon Biological Engineering Technology and Services Co., Shanghai, P.R. China.

\section{Phylogenetic analyses}

The sequences generated from this study were analyzed with related Cytospora taxa and other representative genera in Diaporthales which were derived from GenBank and recent publications (Table 1) (Lawrence et al. 2018, Norphanphoun et al. 2018, Pan et al. 2018, Zhu et al. 2018, NCBI 2019, Fan et al. 2020). The consensus sequences were initially aligned by MAFFT v. 7.310 (Katoh \& Standley 2013) and further improved where necessary by using Bioedit v. 7.0.9.1 (Hall 1999). Individual DNA sequence data from ITS, LSU, ACT and RPB2 were initially analyzed separately for comparing the tree topologies. In addition, a concatenated dataset of the ITS, LSU, ACT and RPB2 gene region was also assembled and analyzed under different optimality criteria. Phylogenetic trees were generated from maximum likelihood (ML), maximum parsimony (MP) and Bayesian inference (BI) analyses.

An evolutionary model for BI was estimated independently for each locus using MrModeltest v. 2.3 (Nylander 2008). The best-fit model with GTR+I+G was selected for each locus under the Akaike Information Criterion (AIC). Bayesian Inference analysis was performed via the web portal CIPRES Science Gateway v. 3.3 (Miller et al. 2010) using MrBayes v. 3.2.6 on XSEDE. Posterior probabilities (PP) (Rannala \& Yang 1996, Zhaxybayeva \& Gogarten 2002) were determined by Markov Chain Monte Carlo Sampling (MCMC). Six simultaneous Markov Chains were run from random trees for 20,000,000 generations and trees were sampled every $100^{\text {th }}$ generation with a total of 200,000 trees. The first $25 \%$ trees representing the burn-in phase were discarded and the remaining trees were used to calculate the posterior probabilities (PP) in the majority rule consensus tree (the standard deviation of split frequencies were reached to 0.01).

A maximum likelihood analysis was performed by Randomized Axelerated Maximum Likelihood (RAxML) using program raxmlGUI v. 1.3 (Silvestro \& Michalak 2012). A general time reversible model (GTR) was applied with a discrete gamma distribution which was complemented 
for each substitution model (Silvestro \& Michalak 2012). The optimal ML tree search was conducted with 1000 rapid bootstrapping. The final tree was selected among suboptimal trees from each run by comparing likelihood scores under the GTR+GAMMAI substitution model.

Table 1 Isolates used in this study and their GenBank accession numbers.

\begin{tabular}{|c|c|c|c|c|c|c|c|c|}
\hline \multirow{2}{*}{ Taxon } & \multirow{2}{*}{ Source * } & \multirow{2}{*}{ Host } & \multirow{2}{*}{ Origin } & \multicolumn{4}{|c|}{ GenBank accession } & \multirow{2}{*}{-Reference } \\
\hline & & & & ITS & LSU & ACT & RPB2 & \\
\hline Cytospora abyssinica & CMW $10181^{\mathrm{T}}$ & Eucalyptus globulus & Wondo Genet, Ethiopia & AY347353 & - & - & - & Adams et al. (2005) \\
\hline C. acaciae & CBS 468.69 & Ceratonia siliqua & Spain, Mallorca & DQ243804 & - & - & - & Adams et al. (2006) \\
\hline C. ailanthicola & CFCC $89970^{\mathrm{T}}$ & Ailanthus altissima & Ningxia, China & MH933618 & MH933653 & MH933526 & MH933592 & Fan et al. (2020) \\
\hline C. ambiens & CFCC 89894 & Pyrus bretschneideri & Ningxia, China & KR045617 & KR045699 & KU710989 & KU710945 & Unpublished \\
\hline C. ampulliformis & MFLUCC 16-0583 ${ }^{\mathrm{T}}$ & Sorbus intermedia & Russia & KY417726 & KY417760 & KY417692 & KY417794 & Norphanphoun et al. (2017) \\
\hline C. amygdali & CBS $144233^{\mathrm{T}}$ & juglans regia & California, USA & MG971853 & - & MG972002 & - & Lawrence et al. (2018) \\
\hline C. atrocirrhata & CFCC $89615^{\mathrm{T}}$ & juglans regia & Qinghai, China & KR045618 & KR045700 & KF498673 & KU710946 & Fan et al. (2015a), Zhu et al. (2018) \\
\hline C. austromontana & CMW $6735^{\mathrm{T}}$ & Eucalyptus pauciflora & Australia & AY347361 & - & - & - & Adams et al. (2005) \\
\hline C. beilinensis & CFCC $50493^{\mathrm{T}}$ & Pinus armandii & Beijing, China & МН933619 & MH933654 & МH933527 & - & Fan et al. (2020) \\
\hline C. berberidis & CFCC $89927^{\mathrm{T}}$ & Berberis dasystachya & China & KR045620 & KR045702 & KU710990 & KU710948 & Liu et al. (2015) \\
\hline C. berkeleyi & StanfordT $3^{\mathrm{T}}$ & Eucalyptus globulus & California, USA & AY347350 & - & - & - & Adams et al. (2005) \\
\hline C. brevispora & CBS $116811^{\mathrm{T}}$ & $\begin{array}{l}\text { Eucalyptus grandis } \times \\
\text { tereticornis }\end{array}$ & $\begin{array}{l}\text { Democratic Republic of } \\
\text { the Congo }\end{array}$ & AF192315 & - & - & - & Adams et al. (2005) \\
\hline C. bungeanae & CFCC $50495^{\mathrm{T}}$ & Pinus bungeana & Shanxi, China & MH933621 & MH933656 & МH933529 & MH933593 & Fan et al. (2020) \\
\hline C. californica & CBS $144234^{\mathrm{T}}$ & Juglans regia & California, USA & MG971935 & - & MG972083 & - & Lawrence et al. (2018) \\
\hline C. carbonacea & CFCC 89947 & Ulmus pumila & Qinghai, China & KR045622 & КР310812 & КР310842 & KU710950 & Yang et al. (2015) \\
\hline C. carbonacea & CFCC 50055 & Ulmus pumila & Shanxi, China & KP281262 & KP310808 & КР310838 & - & Yang et al. (2015) \\
\hline C. carpobroti & CMW $48981^{\mathrm{T}}$ & Carpobrotus edulis & $\begin{array}{l}\text { Cape Town, South } \\
\text { Africa }\end{array}$ & МH382812 & MH411216 & - & - & Jami et al. (2018) \\
\hline C. cedri & MFLUCC 18-1219a & Ostrya carpinifolia & Forlì-Cesena, Italy & MK912132 & MK571760 & MN685814 & MN685823 & This study \\
\hline C. cedri & MFLUCC 18-1219b & Ostrya carpinifolia & Forlì-Cesena, Italy & MK912133 & MK571761 & MN685815 & MN685824 & This study \\
\hline C. cedri & CBS 196.50 & - & Italy & AF192311 & - & - & - & Adams et al. (2002) \\
\hline C. celtidicola & CFCC $50497^{\mathrm{T}}$ & Celtis sinensis & Anhui, China & MH933623 & MH933658 & МH933531 & MH933595 & Fan et al. (2020) \\
\hline C. centravillosa & MFLUCC 16-1206 & Sorbus domestica & Italy & MF190122 & MF190068 & - & MF377600 & Senanayake et al. (2017) \\
\hline C. ceratophora & CBS 192.42 & Taxus baccata & Italy & AY347333 & - & - & - & Adams et al. (2005) \\
\hline C. ceratosperma & MFLUCC 16-0625 & Acer platanoides & Russia & KY563246 & KY563248 & KY563242 & KY563244 & Tibpromma et al. (2017) \\
\hline
\end{tabular}


Table 1 Continued.

\begin{tabular}{|c|c|c|c|c|c|c|c|c|}
\hline \multirow{2}{*}{ Taxon } & \multirow{2}{*}{ Source * } & \multirow{2}{*}{ Host } & \multirow{2}{*}{ Origin } & \multicolumn{4}{|c|}{ GenBank accession } & \multirow{2}{*}{-Reference } \\
\hline & & & & ITS & LSU & ACT & RPB2 & \\
\hline C. ceratospermopsis & CFCC $89626^{\mathrm{T}}$ & Juglans regia & Shaanxi, China & KR045647 & KR045726 & KU711011 & KU710978 & Fan et al. (2020) \\
\hline C. ceratospermopsis & CFCC 89627 & Juglans regia & Shaanxi, China & KR045648 & KR045727 & KU711012 & KU710979 & Fan et al. (2020) \\
\hline C. chrysosperma & CFCC $89982^{\mathrm{T}}$ & Ulmus pumila & Xizang, China & KP281261 & KP310805 & KP310835 & - & Yang et al. (2015) \\
\hline C. cincta & CFCC 89956 & Prunus cerasifera & China & KR045624 & KR045704 & KU710993 & KU710953 & Zhu et al. (2018) \\
\hline C. cinerostroma & CMW $5700^{\mathrm{T}}$ & Eucalyptus globulus & Chile & AY347377 & - & - & - & Adams et al. (2005) \\
\hline C. coenobitica & CBS 283.74 & Betula verrucosa & Netherlands & JX438610 & - & - & - & Adams et al. (2002) \\
\hline C. cotini & MFLUCC 14-1050 ${ }^{\mathrm{T}}$ & Cotinus coggygria & Russia & KX430142 & KX430143 & - & KX430144 & Norphanphoun et al. (2017) \\
\hline C. cotini & MFLUCC 18-1203 & Ostrya carpinifolia & Forlì-Cesena, Italy & MK912134 & MK571762 & MN685816 & MN685825 & This study \\
\hline C. curvata & MFLUCC 15-0865 ${ }^{\mathrm{T}}$ & Salix alba & Russia & KY417728 & - & KY417694 & - & Norphanphoun et al. (2017) \\
\hline C. cypri & CBS $201.42^{\mathrm{T}}$ & Syringa sp. & Switzerland & DQ243801 & - & - & - & Adams et al. (2006) \\
\hline C. davidiana & CXY1350 ${ }^{\mathrm{T}}$ & Populus davidiana & China & KM034870 & - & - & - & Wang et al. (2015) \\
\hline C. decorticans & CBS 116.21 & Fagus sylvatica & Netherlands & AY347335 & - & - & - & Adams et al. (2005) \\
\hline C. diatrypelloidea & CMW $8549^{\mathrm{T}}$ & Eucalyptus globulus & Orbost, Australia & AY347368 & - & - & - & Adams et al. (2005) \\
\hline C. diopuiensis & MFLUCC 18-1419 T & Undefined wood & Chiang Mai, Thailand & MK912137 & MK571765 & MN685819 & - & This study \\
\hline $\begin{array}{l}\text { C. diopuiensis = } \\
\text { "Phomopsis theae" }\end{array}$ & GJJM16 & - & - & JN638438 & - & - & - & Jayanthi et al. (2018) \\
\hline C. disciformis & CMW $6509^{\mathrm{T}}$ & Eucalyptus grandis & Uruguay & AY347374 & - & - & - & Adams et al. (2005) \\
\hline C. donetzica & MFLUCC 16-0574 ${ }^{\mathrm{T}}$ & Rosa sp. & Russia & KY417731 & KY417765 & KY417697 & KY417799 & Norphanphoun et al. (2017) \\
\hline C. elaeagni & CFCC $89632^{\mathrm{T}}$ & Elaeagnus angustifolia & Ningxia, China & KR045626 & KR045706 & KU710995 & KU710955 & Fan et al. (2015b), Zhu et al. (2018) \\
\hline C. eriobotryae & IMI136523 ${ }^{\mathrm{T}}$ & Eriobotrya japonica & India & AY347327 & - & - & - & Adams et al. (2005) \\
\hline C. erumpens & MFLUCC 16-0580 ${ }^{\mathrm{T}}$ & Salix $\times$ fragilis & Russia & KY417733 & KY417767 & KY417699 & KY417801 & Norphanphoun et al. (2017) \\
\hline C. eucalypti & LSEQ & Sequoia sempervirens & California, USA & AY347340 & - & - & - & Adams et al. (2005) \\
\hline C. eucalyptina & CMW 5882 & Eucalyptus grandis & Cali, Columbia & AY347375 & - & - & - & Adams et al. (2005) \\
\hline C. eugeniae & CMW 8648 & Eugenia sp. & Indonesia & AY347344 & - & - & - & Adams et al. (2005) \\
\hline C. euonymicola & CFCC $50499^{\mathrm{T}}$ & $\begin{array}{l}\text { Euonymus } \\
\text { kiautschovicus }\end{array}$ & Shaanxi, China & МН933628 & MH933662 & MH933535 & МH933598 & Fan et al. (2020) \\
\hline C. euonymina & CFCC $89993^{\mathrm{T}}$ & $\begin{array}{l}\text { Euonymus } \\
\text { kiautschovicus }\end{array}$ & Shaanxi, China & MH933630 & MH933664 & MH933537 & MH933600 & Fan et al. (2020) \\
\hline C. fabianae & ATCC $96150^{\mathrm{T}}$ & Eucalyptus nitens & Tasmania, Australia & AY347358 & - & - & - & Adams et al. (2005) \\
\hline C. fraxinigena & MFLUCC 14-0868 ${ }^{\mathrm{T}}$ & Fraxinus ornus & Italy & MF190133 & MF190078 & - & - & Senanayake et al. (2017) \\
\hline
\end{tabular}


Table 1 Continued.

\begin{tabular}{|c|c|c|c|c|c|c|c|c|}
\hline \multirow{2}{*}{ Taxon } & \multirow{2}{*}{ Source * } & \multirow{2}{*}{ Host } & \multirow{2}{*}{ Origin } & \multicolumn{4}{|c|}{ GenBank accession } & \multirow{2}{*}{-Reference } \\
\hline & & & & ITS & LSU & ACT & RPB2 & \\
\hline C. fraxinigena & BBH42442 & Fraxinus ornus & Italy & MF190134 & MF190079 & - & - & Senanayake et al. (2017) \\
\hline C. friesii & CBS 194.42 & Abies alba & Switzerland & AY347328 & - & - & - & Adams et al. (2005) \\
\hline C. galegicola & MFLUCC 18-1199 T & Galega officinalis & Forlì-Cesena, Italy & MK912128 & MK571756 & MN685810 & MN685820 & This study \\
\hline C. gelida & MFLUCC 16-0634 ${ }^{\mathrm{T}}$ & Cotinus coggygria & Russia & KY563245 & KY563247 & KY563241 & KY563243 & Tibpromma et al. (2017) \\
\hline C. germanica & CXY1322 & Elaeagnus охусагра & China & JQ086563 & JX524617 & - & - & Zhang et al. (2013) \\
\hline C. gigalocus & CFCC $89620^{\mathrm{T}}$ & Juglans regia & Qinghai, China & KR045628 & KR045708 & KU710997 & KU710957 & Fan et al. (2015a), Zhu et al. (2018) \\
\hline C. gigaspora & CFCC $89634^{\mathrm{T}}$ & Salix psammophila & Shaanxi, China & KF765671 & KF765687 & KU711000 & KU710960 & Fan et al. (2015b), Zhu et al. (2018) \\
\hline C. granati & CBS $144237^{\mathrm{T}}$ & Punica granatum & California, USA & MG971799 & - & MG971949 & - & Lawrence et al. (2018) \\
\hline C. gutnerae & 214 & Platanus orientalis & Iran & EF447365 & - & - & - & Fotouhifar et al. (2010) \\
\hline C. japonica & CBS 375.29 & Prunus persica & Japan & AF191185 & - & - & - & Adams et al. (2002) \\
\hline C. joaquinensis & CBS $144235^{\mathrm{T}}$ & Populus deltoides & California, USA & MG971895 & - & MG972044 & - & Lawrence et al. (2018) \\
\hline C. junipericola & BBH42444 & $\begin{array}{l}\text { Juniperus communis } \\
\text { (Cupressaceae) }\end{array}$ & Italy & MF190125 & MF190072 & - & - & Senanayake et al. (2017) \\
\hline C. junipericola & MFLU $17-0882^{\mathrm{T}}$ & $\begin{array}{l}\text { Juniperus communis } \\
\text { (Cupressaceae) }\end{array}$ & Italy & MF190126 & MF190071 & - & - & Senanayake et al. (2017) \\
\hline C. juniperina & CFCC $50501^{\mathrm{T}}$ & Juniperus przewalskii & Sichuan, China & MH933632 & МH933666 & МH933539 & MH933602 & Fan et al. (2020) \\
\hline C. kantschavelii & $287-2$ & Populus deltoides & Iran & EF447367 & - & - & - & Fotouhifar et al. (2010) \\
\hline C. kunzei & CBS 118556 & Pinus radiata & $\begin{array}{l}\text { Eastern Cape, South } \\
\text { Africa }\end{array}$ & DQ243791 & - & - & - & Adams et al. (2006) \\
\hline C. leucostoma & CFCC 50015 & $\begin{array}{l}\text { Sorbus } \\
\text { pohuashanensis }\end{array}$ & China & KR045634 & KR045714 & KU711002 & KU710963 & Yang et al. (2015) \\
\hline C. longiostiolata & MFLUCC $16-0628^{\mathrm{T}}$ & Salix $\times$ fragilis & Russia & KY417734 & KY417768 & KY417700 & KY417802 & Norphanphoun et al. (2017) \\
\hline C. longispora & CBS $144236^{\mathrm{T}}$ & Prunus domestica & California, USA & MG971905 & - & MG972054 & - & Lawrence et al. (2018) \\
\hline C. lumnitzericola & MFLUCC 17-0508 ${ }^{\mathrm{T}}$ & Lumnitzera racernosa & Phetchaburi, Thailand & MG975778 & MH253453 & MH253457 & MH253461 & Norphanphoun et al. (2018) \\
\hline C. mali & CFCC 50031 & Crataegus sp. & Shanxi, China & KR045636 & KR045716 & KU711004 & KU710965 & Zhu et al. (2018) \\
\hline C. malicola & CBS 118570 & Malus domestica & Michigan, USA & DQ243802 & - & - & - & Adams et al. (2005) \\
\hline C. mali-sylvestris & MFLUCC 16-0638 & $\begin{array}{l}\text { Malus sylvestris } \\
\text { (Rosaceae) }\end{array}$ & Russia & KY885017 & KY885018 & KY885019 & KY885020 & Hyde et al. (2017) \\
\hline C. melnikii & MFLUCC $15-0851^{\mathrm{T}}$ & Malus domestica & Russia & KY417735 & KY417769 & KY417701 & KY417803 & Norphanphoun et al. (2017) \\
\hline C. mougeotii & ATCC 44994 & Picea abies & Norway & AY347329 & - & - & - & Adams et al. (2005) \\
\hline
\end{tabular}


Table 1 Continued.

\begin{tabular}{|c|c|c|c|c|c|c|c|c|}
\hline \multirow{2}{*}{ Taxon } & \multirow{2}{*}{ Source * } & \multirow{2}{*}{ Host } & \multirow{2}{*}{ Origin } & \multicolumn{4}{|c|}{ GenBank accession } & \multirow{2}{*}{-Reference } \\
\hline & & & & ITS & LSU & ACT & RPB2 & \\
\hline C. multicollis & CBS $105.89^{\mathrm{T}}$ & $\begin{array}{l}\text { Quercus ilex subsp. } \\
\text { rotundifolia }\end{array}$ & Spain & DQ243803 & - & - & - & Adams et al. (2006) \\
\hline C. myrtagena & HiloTib1 & Tibouchina urvilleana & Hawaii, USA & AY347363 & - & - & - & Adams et al. (2005) \\
\hline C. nitschkii & CMW10180 ${ }^{\mathrm{T}}$ & Eucalyptus globulus & Wondo Genet, Ethiopia & AY347356 & - & - & - & Adams et al. (2005) \\
\hline C. nitschkii & CMW10184 & Eucalyptus globulus & Wondo Genet, Ethiopia & AY347355 & - & - & - & Adams et al. (2005) \\
\hline C. nivea & CFCC $89642^{\mathrm{T}}$ & Salix psammophila & Yulin, Shanxi, China & KF765684 & KF765700 & KF765732 & KF765716 & Fan et al. (2015b), Zhu et al. (2018) \\
\hline C. oleicola & CBS $144248^{\mathrm{T}}$ & Olea europaea & California, USA & MG971944 & - & MG972098 & - & Lawrence et al. (2018) \\
\hline C. palm & CXY1280 ${ }^{\mathrm{T}}$ & Cotinus coggygria & Beijing, China & JN411939 & - & - & - & Zhang et al. (2014) \\
\hline C. parakantschavelii & MFLUCC $15-0857^{\mathrm{T}}$ & Populus $\times$ sibirica & Russia & KY417738 & KY417772 & KY417704 & KY417806 & Norphanphoun et al. (2017) \\
\hline C. parapersoonii & $\mathrm{T} 28.1^{\mathrm{T}}$ & Prunus persicae & Michigan, USA & AF191181 & - & - & - & Adams et al. (2002) \\
\hline C. parapistaciae & CBS $144506^{\mathrm{T}}$ & Pistacia vera & California, USA & MG971804 & - & MG971954 & - & Lawrence et al. (2018) \\
\hline C. parasitica & MFLUCC $15-0507^{\mathrm{T}}$ & Malus domestica & Russia & KY417740 & KY417774 & KY417706 & KY417808 & Norphanphoun et al. (2017) \\
\hline C. paratranslucens & MFLUCC 15-0506 ${ }^{\mathrm{T}}$ & $\begin{array}{l}\text { Populus alba var. } \\
\text { bolleana }\end{array}$ & Otto & KY417741 & KY417775 & KY417707 & KY417809 & Norphanphoun et al. (2017) \\
\hline C. piceae & CFCC $52841^{\mathrm{T}}$ & Picea crassifolia & Xinjiang, China & MH820398 & MH820391 & MH820406 & MH820395 & Pan et al. (2018) \\
\hline C. pingbianensis & MFLUCC 18-1204 ${ }^{\mathrm{T}}$ & Undefined wood & Yunnan, China & MK912135 & MK571763 & MN685817 & MN685826 & This study \\
\hline C. pini & CBS $224.52^{\mathrm{T}}$ & Pinus strobus & New York & AY347316 & - & - & - & Adams et al. (2005) \\
\hline C. pistaciae & CBS $144238^{\mathrm{T}}$ & Pistacia vera & California, USA & MG971802 & - & MG971952 & - & Lawrence et al. (2018) \\
\hline C. platycladi & CFCC $50504^{\mathrm{T}}$ & Platycladus orientalis & Yunnan, China & МН933645 & МН933679 & МH933552 & МН933610 & Fan et al. (2020) \\
\hline C. platycladi & CFCC 50505 & Platycladus orientalis & Yunnan, China & МН933646 & МH933680 & MH933553 & MH933611 & Fan et al. (2020) \\
\hline C. platycladicola & CFCC $50038^{\mathrm{T}}$ & Platycladus orientalis & Gansu, China & KT222840 & MH933682 & MH933555 & МН933613 & Fan et al. (2020) \\
\hline C. plurivora & CBS $144239^{\mathrm{T}}$ & Olea europaea & California, USA & MG971861 & - & MG972010 & - & Lawrence et al. (2018) \\
\hline C. populicola & CBS $144240^{\mathrm{T}}$ & Populus deltoides & California, USA & MG971891 & - & MG972040 & - & Lawrence et al. (2018) \\
\hline C. populina & CFCC $89644^{\mathrm{T}}$ & Salix psammophila & Shanxi, China & KF765686 & KF765702 & KU711007 & KU710969 & Fan et al. (2015b), Zhu et al. (2018) \\
\hline C. populinopsis & CFCC $50032^{\mathrm{T}}$ & Sorbus aucuparia & Ningxia, China & MH933648 & MH933683 & MH933556 & MH933614 & Fan et al. (2020) \\
\hline C. predappioensis & MFLUCC 18-1202 & Ostrya carpinifolia & Forlì-Cesena, Italy & MK912131 & MK571759 & MN685813 & MN685822 & This study \\
\hline C. predappioensis & MFLUCC $17-2458^{\mathrm{T}}$ & Platanus hybrida & Italy & MG873484 & MG873480 & - & - & Hyde et al. (2018) \\
\hline C. predappioensis & MFLUCC 17-0327 & Platanus hybrida & Italy & MH253451 & MH253452 & MH253449 & MH253450 & Hyde et al. (2018) \\
\hline C. predappioensis & MFLUCC 18-1205 & Cupressus sp. & Yunnan, China & MK912136 & MK571764 & MN685818 & MN685827 & This study \\
\hline C. pruinopsis & CFCC $50034^{\mathrm{T}}$ & Ulmus pumila & Shanxi, China & KP281259 & КР310806 & КР310836 & KU710970 & Yang et al. (2015) \\
\hline
\end{tabular}


Table 1 Continued.

\begin{tabular}{|c|c|c|c|c|c|c|c|c|}
\hline \multirow{2}{*}{ Taxon } & \multirow{2}{*}{ Source * } & \multirow{2}{*}{ Host } & \multirow{2}{*}{ Origin } & \multicolumn{4}{|c|}{ GenBank accession } & \multirow{2}{*}{-Reference } \\
\hline & & & & ITS & LSU & ACT & RPB2 & \\
\hline C. pruinosa & CFCC 50036 & Syzygium aromaticum & Qinghai, China & KP310800 & KP310802 & KP310832 & - & Yang et al. (2015) \\
\hline C. prunicola & MFLUCC 18-1200 & Quercus pubescens & Forlì-Cesena, Italy & MK912129 & MK571757 & MN685811 & - & This study \\
\hline C. prunicola & MFLU 17-0995 ${ }^{\mathrm{T}}$ & Prunus sp. & Italy & MG742350 & MG742351 & MG742353 & MG742352 & Hyde et al. (2018) \\
\hline C. pubescentis & MFLUCC $18-1201^{\mathrm{T}}$ & Quercus pubescens & Forlì-Cesena, Italy & MK912130 & MK571758 & MN685812 & MN685821 & This study \\
\hline C. quercicola & MFLUCC $14-0867^{\mathrm{T}}$ & Quercus sp. & Italy & MF190129 & MF190073 & - & - & Senanayake et al. (2017) \\
\hline C. quercicola & BBH42443 & Quercus sp. & Italy & MF190128 & MF190074 & - & - & Senanayake et al. (2017) \\
\hline C. rhizophorae & MUCC302 & Eucalyptus grandis & Australia & EU301057 & - & - & - & Unpublished \\
\hline C. rhodophila & ATCC 38695 & Rosa sp. & - & DQ243809 & - & - & - & Yang et al. (2015) \\
\hline C. ribis & CFCC $50026^{\mathrm{T}}$ & Ulmus pumila & Qinghai, China & KP281267 & КР310813 & КР310843 & KU710972 & Yang et al. (2015) \\
\hline C. rosae & MFLUCC $14-0845^{\mathrm{T}}$ & Rosa canina & Italy & MF190131 & MF190075 & - & - & Senanayake et al. (2017) \\
\hline C. rosae & $\begin{array}{l}\text { MFLUCC 17-1664 } \\
(\mathrm{BBH} 42447)\end{array}$ & Rosa canina & Italy & MF190130 & MF190076 & - & - & Senanayake et al. (2017) \\
\hline C. rosarum & 218 & Rosa canina & Iran & EF447387 & - & - & - & Fotouhifar et al. (2010) \\
\hline C. rostrata & CFCC $89909^{\mathrm{T}}$ & Salix cupularis & Gansu, China & KR045643 & KR045722 & KU711009 & KU710974 & Fan et al. (2014b), Zhu et al. (2018) \\
\hline C. rusanovii & MFLUCC 15-0854 ${ }^{\mathrm{T}}$ & Salix babylonica & Russia & KY417744 & KY417778 & KY417710 & KY417812 & Norphanphoun et al. (2017) \\
\hline C. sacculus & HMBF281 & Juglans regia & China & KF225615 & KF225629 & KF498678 & - & Fan et al. (2015a), Zhu et al. (2018) \\
\hline C. sacculus & HMBF282 & Juglans regia & China & KF225616 & KF225630 & KF498679 & - & Fan et al. (2015a), Zhu et al. (2018) \\
\hline C. sacculus & CFCC $89624^{\mathrm{T}}$ & Juglans regia & Shaanxi, China & KR045645 & KR045724 & - & KU710976 & Fan et al. (2015a), Zhu et al. (2018) \\
\hline C. salicacearum & MFLUCC 15-0509 ${ }^{\mathrm{T}}$ & Salix alba & Russia & KY417746 & KY417780 & KY417712 & KY417814 & Norphanphoun et al. (2017) \\
\hline C. salicicola & MFLUCC 15-0866 & Salix alba & Russia & KY417749 & KY417783 & KY417715 & KY417817 & Norphanphoun et al. (2017) \\
\hline C. salicina & MFLUCC $15-0862^{\mathrm{T}}$ & Salix sp. & Russia & KY417750 & KY417784 & KY417716 & KY417818 & Norphanphoun et al. (2017) \\
\hline C. schulzeri & CFCC 50040 & Malus domestica & Ningxia, China & KR045649 & KR045728 & KU711013 & KU710980 & Unpublished \\
\hline C. sibiraeae & CFCC $50045^{\mathrm{T}}$ & Sibiraea angustata & Gansu, China & KR045651 & KR045730 & KU711015 & KU710982 & Liu et al. (2015) \\
\hline C. sophorae & CFCC 89598 & $\begin{array}{l}\text { Styphnolobium } \\
\text { japonicum }\end{array}$ & Gansu, China & KR045654 & KR045733 & KU711018 & KU710985 & Fan et al. 2014a, Zhu et al. (2018) \\
\hline C. sophoricola & CFCC $89595^{\mathrm{T}}$ & $\begin{array}{l}\text { Styphnolobium } \\
\text { japonicum var. pendula }\end{array}$ & Gansu, China & KR045655 & KR045734 & KU711019 & KU710986 & Fan et al. 2014a, Zhu et al. (2018) \\
\hline C. sophoriopsis & CFCC $89600^{\mathrm{T}}$ & $\begin{array}{l}\text { Styphnolobium } \\
\text { japonicum }\end{array}$ & Gansu, China & KR045623 & КР310804 & KU710992 & KU710951 & Fan et al. (2020) \\
\hline C. sorbi & MFLUCC 16-0631 ${ }^{\mathrm{T}}$ & Sorbus aucuparia & Russia & KY417752 & KY417786 & KY417718 & KY417820 & Norphanphoun et al. (2017) \\
\hline
\end{tabular}


Table 1 Continued.

\begin{tabular}{|c|c|c|c|c|c|c|c|c|}
\hline \multirow{2}{*}{ Taxon } & \multirow{2}{*}{ Source * } & \multirow{2}{*}{ Host } & \multirow{2}{*}{ Origin } & \multicolumn{4}{|c|}{ GenBank accession } & \multirow{2}{*}{-Reference } \\
\hline & & & & ITS & LSU & ACT & RPB2 & \\
\hline C. sorbicola & MFLUCC 16-0584 ${ }^{\mathrm{T}}$ & Acer pseudoplatanus & Russia & KY417755 & KY417789 & KY417721 & KY417823 & Norphanphoun et al. (2017) \\
\hline C. sordida & HMBF159 & Juglans regia & China & KF225613 & KF225627 & KF498676 & - & Fan et al. (2015a) \\
\hline C. spiraeae & CFCC $50049^{\mathrm{T}}$ & Spiraea salicifolia & Gansu, China & MG707859 & MG707643 & MG708196 & MG708199 & Zhu et al. (2018) \\
\hline C. subclypeata & CBS 117.67 & $\begin{array}{l}\text { Rhododendron } \\
\text { ponticum }\end{array}$ & Netherlands & AY347331 & - & - & - & Adams et al. (2005) \\
\hline C. tamaricicola & CFCC $50508^{\mathrm{T}}$ & Tamarix chinensis & Yunnan, China & MH933652 & MH933687 & MH933560 & МH933617 & Fan et al. (2020) \\
\hline C. tanaitica & MFLUCC $14-1057^{\mathrm{T}}$ & Betula pubescens & Russia & KT459411 & KT459412 & KT459413 & - & Ariyawansa et al. (2015) \\
\hline C. terebinthi & 227 & Pistacia khinjuk & Iran & EF447402 & - & - & - & Fotouhifar et al. (2010) \\
\hline C. thailandica & MFLUCC $17-0262^{\mathrm{T}}$ & $\begin{array}{l}\text { Xylocarpus } \\
\text { moluccensis }\end{array}$ & Ranong, Thailand & MG975776 & MH253455 & MH253459 & MH253463 & Norphanphoun et al. (2018) \\
\hline C. thailandica & MFLUCC 17-0263 & $\begin{array}{l}\text { Xylocarpus } \\
\text { moluccensis }\end{array}$ & Ranong, Thailand & MG975777 & MH253456 & MH253460 & MH253464 & Norphanphoun et al. (2018) \\
\hline C. tibouchinae & CPC $26333^{\mathrm{T}}$ & $\begin{array}{l}\text { Tibouchina } \\
\text { semidecandra }\end{array}$ & La Reunion, France & KX228284 & KX228335 & - & - & Crous et al. (2013) \\
\hline C. ulmi & MFLUCC 15-0863 ${ }^{\mathrm{T}}$ & Ulmus minor & Russia & KY417759 & KY417793 & KY417725 & KY417827 & Norphanphoun et al. (2017) \\
\hline C. ulmicola & MFLUCC $18-1227^{\mathrm{T}}$ & $\begin{array}{l}\text { Ulmus pumila } \\
\text { (Ulmaceae) }\end{array}$ & Russia & MH940220 & MH940218 & MH940216 & - & Phookamsak et al. (2019) \\
\hline C. valsoidea & CMW $4309^{\mathrm{T}}$ & Eucalyptus grandis & $\begin{array}{l}\text { North Sumatra, } \\
\text { Indonesia }\end{array}$ & AF192312 & - & - & - & Adams et al. (2005) \\
\hline C. variostromatica & CMW $6766^{\mathrm{T}}$ & Eucalyptus globulus & Australia & AY347366 & - & - & - & Adams et al. (2005) \\
\hline C. vinacea & CBS $141585^{\mathrm{T}}$ (Cyt5) & Eucalyptus globulus & New Hampshire, USA & KX256256 & - & - & - & Lawrence et al. (2017) \\
\hline C. xylocarpi & MFLUCC 17-0251 ${ }^{\mathrm{T}}$ & Xylocarpus granatum & Ranong, Thailand & MG975775 & MH253454 & MH253458 & MH253462 & Norphanphoun et al. (2018) \\
\hline Diaporthe eres & CBS 145040 & Lactuca satia & Netherlands & MK442579 & MK442521 & MK442634 & MK442663 & Crous et al. (2019) \\
\hline
\end{tabular}

* ABBREVIATIONS: ATCC: American Type Culture Collection, Manassas, America; BBH: National Science and Technology Development Agency, Thailand; CBS: Westerdijk Fungal Biodiversity Institute, Utrecht, Netherlands; CFCC: China Forestry Culture Collection Center; CMW: The culture collection of Mike Wingfield housed at TPCP, FABI, University of Pretoria. IMI: International Mycological Institute, CABI-Bioscience, Egham, Bakeham Lane, UK; CPC: Culture collection of Pedro Crous, housed at CBS; MFLU: Mae Fah Luang University Herbarium Collection; MFLUCC: Mae Fah Luang University Culture Collection, Chiang Rai, Thailand. ${ }^{\mathrm{T}}$ denotes the sources of holotype and epitype. The newly generated sequences are in blue. 
Maximum parsimony analysis (MP) was performed by PAUP (Phylogenetic Analysis Using Parsimony) v. 4.0b10 (Swofford 2002) using the heuristic search option. Starting tree(s) were obtained via stepwise addition with 1,000 replicates of random sequence additions and the branch swapping was performed by using tree-bisection-reconnection (TBR) swapping algorithm. Maxtrees were set up at 1000 with all characters were treated as unordered and of equal weight. Gaps were treated as missing data and the branches of zero length were collapsed. All multiple equally parsimonious trees were saved. Clade stability was assessed using a bootstrap (BT) analysis with 1000 replicates, each with 10 replicates of random stepwise addition of taxa (Hillis \& Bull 1993). Tree Length [TL], Consistency Index [CI], Retention Index [RI], Relative Consistency Index [RC] and Homoplasy Index [HI]) were calculated for all parsimonious trees. The KishinoHasegawa tests (Kishino \& Hasegawa 1989) were performed to compare tree topologies obtained under different optimality criteria.

Phylograms were viewed in FigTree v. 1.4.2 (Rambaut 2012). The resulting tree was edited and annotated in Microsoft Power Point (2016) and converted to jpeg file in Adobe Photoshop CS6 software (Adobe Systems, USA). Sequences derived from this study were deposited in GenBank (Table 1). The final alignment and tree have been deposited in TreeBASE under submission ID: 25123 (TreeBASE 2019).

\section{Results}

\section{Phylogenetic analysis}

Phylogenetic analysis of a combined ITS, LSU, ACT and RPB2 dataset was used to determine the taxonomic placement of our new taxa and other Cytospora species. Phylogenetic analyses obtained from ML, MP and BI analyses resulted in trees with similar topologies and were not significantly different (data not shown). Trees recovered from single gene analyses did not result in any topological conflicts with respect to phylogenies generated with the combined dataset (data not shown). The sequence data comprises 147 Cytospora taxa with Diaporthe eres (CBS 145040) as the outgroup taxon (Crous et al. 2019). The best scoring ML tree (shown in Fig. 1) with the final ML optimization likelihood value of $-23739.011018(\mathrm{ln})$ is selected to represent and discuss the phylogenetic relationships among taxa. The dataset for maximum parsimony comprised 2761 characters (including the gaps), of which 1868 are constant characters, 664 are parsimonyinformative characters and 229 are variable parsimony-uninformative characters, yielded 10 equally most parsimonious trees and the first parsimonious tree was represented as the best tree (TL = 4069, $\mathrm{CI}=0.342, \mathrm{RI}=0.728, \mathrm{RC}=0.249, \mathrm{HI}=0.658$ ). The $\mathrm{BI}$ analysis for final split frequency critical value for the topological convergence diagnostic is 0.009995 .

The phylogenetic result (Fig. 1) depicts the relationships of other Cytospora taxa within Diaporthales which is congruent to phylogeny recovered by Norphanphoun et al. (2018) and Pan et al. (2018). Most of the isolates clustered together with other Cytospora species and eight species can be reorganized in the tree. Six taxa grouped together with ex-type strains of known species and can be identified as C. cedri, C. cotini, C. predappioensis and C. prunicola; and four isolates represent phylogenetically distinct species and are introduced as the new species, $C$. diopuiensis, $C$. galegicola, $C$. pingbianensis and $C$. pubescentis. The details of the relationships of the new taxa with others are discussed in the notes.

\section{Taxonomy}

Cytospora cedri Syd., P. Syd. \& E.J. Butler, Annls mycol. 14(3/4): 193 (1916)

Index Fungorum number: IF 184521; Facesoffungi number: FoF 05104

Fig. 2

Saprobic on the bark. Sexual morph Stromata 1048-1422 $\mu$ m wide, with the poorly developed interior, solitary to gregarious, immersed, becoming raised to erumpent the bark by the ostiolar canal, dark brown to black, glabrous, circular in shape, arranged with conspicuous, clustered, roundish to cylindrical prominent ostioles. Ascomata (excluding necks) 212-334 $\mu \mathrm{m}$ 


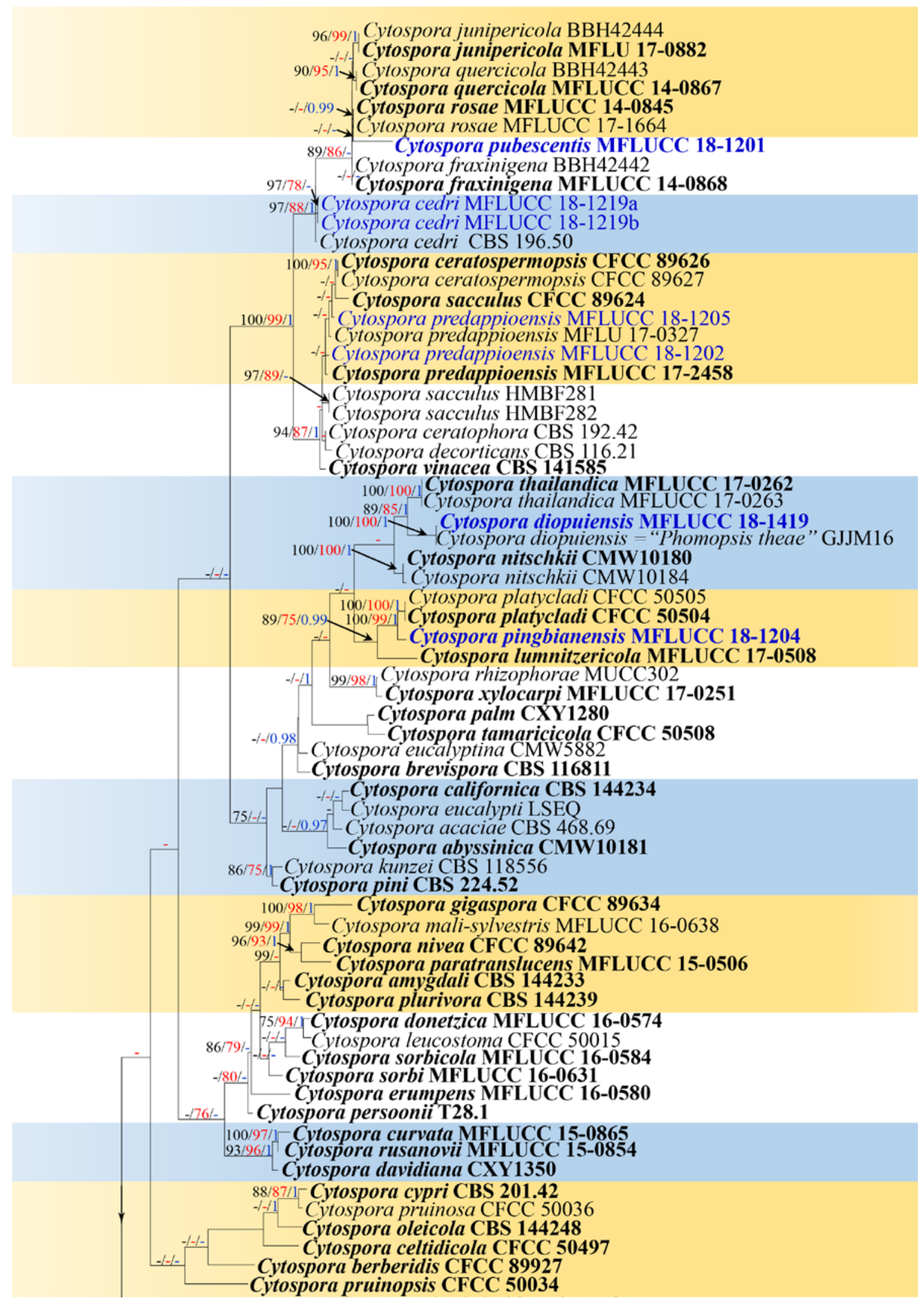

Figure 1 - Phylogenetic tree generated from MP analysis based on a combined dataset of ITS, LSU, ACT and RPB2 sequence data. Bootstrap support values for ML (back) and MP (red) equal to or greater than $75 \%$ are shown above the nodes. The BI values (blue) greater than 0.95 are also indicated above the nodes. The new isolates are in blue and ex-type strains are in bold. The tree is rooted to Diaporthe eres (CBS 145040). 


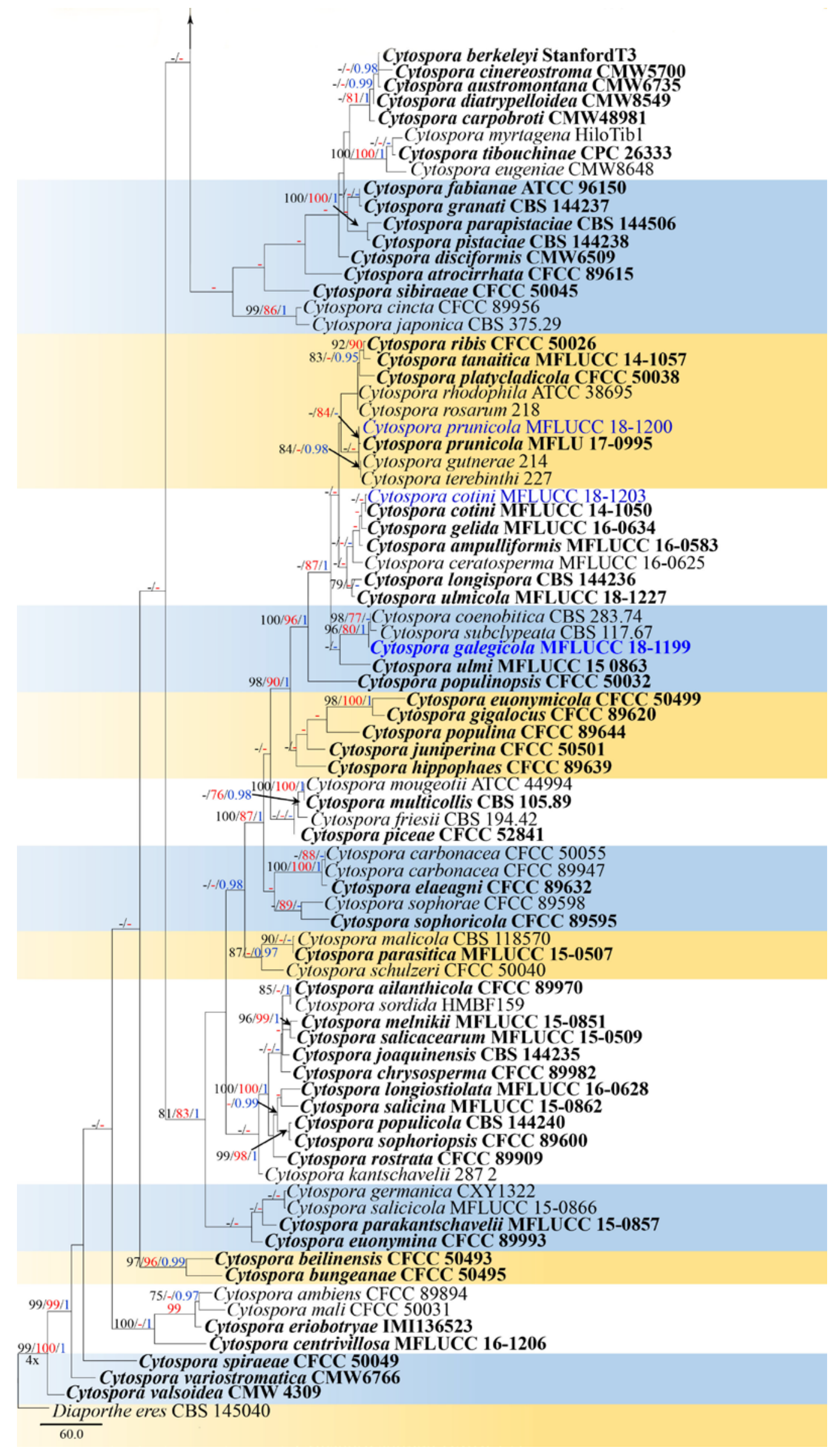

Figure 1 - Continued. 
high, $222-373 \mu \mathrm{m}$ diam. $(\bar{x}=273 \times 297 \mu \mathrm{m}, \mathrm{n}=30)$, perithecial, immersed in a stroma, dark brown to brown, globose to subglobose, glabrous, individual ostiole with the neck. Ostiolar canal 287-493 $\mu \mathrm{m}$ high, 59-90 $\mu \mathrm{m}$ diam. $(\bar{x}=390 \times 75 \mu \mathrm{m}, \mathrm{n}=18)$, cylindrical, sulcate, periphysate. Peridium 25-38 $\mu \mathrm{m}$ wide, composed of two section layers, outer section comprising 3-5 layers, of relatively small, brown to dark brown, thick-walled cells, arranged in textura angularis, the inner part comprising 2-3 layers of hyaline cells of textura angularis. Hamathecium comprising only asci. Asci (30-)32-39(-42) $\times(4-) 4.5-6(-6.5) \mu \mathrm{m}(\bar{x}=35 \times 5.2 \mu \mathrm{m}, \mathrm{n}=35), 8$-spored, unitunicate, clavate, sessile, apically rounded to truncate, with a J- apical ring. Ascospores (5.5-)7-8.5(-10) $\times$ (1.5-)1.8-2.5(-3) $\mu \mathrm{m}(\bar{x}=7.6 \times 2 \mu \mathrm{m}, \mathrm{n}=110)$, overlapping 1-2-seriate, hyaline, allantoid, aseptate, smooth-walled. Asexual morph Undetermined.

Culture characteristics - Ascospores germinating on PDA within 24 hrs. Germ tubes produced from all sides. Colonies on PDA reaching 5-5.5 cm diam. after 15 days at room temperature, colonies circular to irregular, medium dense, flat or effuse, slightly raised, with edge fimbriate, fluffy to fairy fluffy, dark brown from above, dark brown to black from below; not producing pigments in agar.

Material examined - ITALY, near Galeata (Province of Forlì-Cesena [FC]), on a dead land branch of Ostrya carpinifolia, 13 April 2017, E. Camporesi, IT 3289C (MFLU 18-1387, KUNHKAS 100917), living culture, MFLUCC 18-1219.

Notes - Cytospora cedri was reported by Sydow et al. (1916) as a coelomycete which is characterized by having black stromata and allantoid conidia. There are no records of the sexual morph (Adams et al. 2002, 2005, 2006). The phylogenetic result (Fig. 1) shows that our isolates (MFLUCC 18-1219a and MFLUCC 18-1219b) cluster together with C. cedri (CBS 196.50) with support (57\% ML, 58\% MP and 0.56 PP). The single gene comparison of ITS (Table 4) showed that there is no sequence difference among these three isolates. Therefore, based on the guidelines of Jeewon \& Hyde (2016), we identify our isolates (MFLUCC 18-1219a and MFLUCC 18-1219b) as $C$. cedri and provide the first sexual morph description for the species.

Cytospora cotini Norph., Bulgakov \& K.D. Hyde, Fungal Diversity 80: 176 (2016)

Fig. 3

Index Fungorum number: IF552231; Facesoffungi number: FoF02365

Saprobic on the bark. Sexual morph Stromata 1190-2098 $\mu \mathrm{m}$ wide, with the poorly developed interior, solitary to gregarious, immersed, becoming raised to erumpent by the ostiolar canal, dark brown to black, glabrous, circular in shape, arranged with conspicuous, clustered, roundish to cylindrical prominent ostioles. Ascomata (excluding necks) 183-386 $\mu \mathrm{m}$ high, 364-613 $\mu \mathrm{m}$ diam. $(\bar{x}=284 \times 489 \mu \mathrm{m}, \mathrm{n}=15)$, perithecial, immersed in a stroma, brown to dark brown, globose to subglobose, glabrous, individual ostiole with the neck. Ostiolar canal 250-310 $\mu \mathrm{m}$ high, 120-155 $\mu \mathrm{m}$ diam. $(\bar{x}=276 \times 139 \mu \mathrm{m}, \mathrm{n}=10$ ), cylindrical, sulcate, periphysate. Peridium 49-84 $\mu \mathrm{m}$ wide, composed of two section layers, outer section comprising 5-10 layers, of relatively small, brown to dark brown, thick-walled cells, arranged in textura angularis, the inner part comprising 3-5 layers of hyaline cells of textura angularis. Hamathecium comprising only asci. Asci (56-)61$71(-85) \times(6.5-) 7.5-9.5(-11) \mu \mathrm{m}(\bar{x}=66 \times 8.4 \mu \mathrm{m}, \mathrm{n}=50), 8$-spored, unitunicate, clavate, short stalks, apically rounded to truncate, with a J-, refractive apical ring. Ascospores (10.5-)12.5-15(17) $\times(2.5-) 3-4(-4.5) \mu \mathrm{m}(\bar{x}=14 \times 3.5 \mu \mathrm{m}, \mathrm{n}=250)$, overlapping 1-2-seriate, hyaline, allantoid, aseptate, smooth-walled. Asexual morph Undetermined.

Culture characteristics - Ascospores germinating on PDA within 24 hrs. Germ tubes produced from all sides. Colonies on PDA reaching 5-5.5 cm diam. after 7 days at room temperature, colonies circular to irregular, medium dense, flat or effuse, slightly raised, with edge fimbriate, fluffy to fairy fluffy, white from above, white to yellow from below; not producing pigments in agar.

Material examined - ITALY, Corniolo, Santa Sofia (Province of Forlì-Cesena [FC]), on a dead land branch of Ostrya carpinifolia, 29 March 2017, E. Camporesi, IT 3294 (MFLU 17-0864, KUN-HKAS 100919), living culture, MFLUCC 18-1203. 

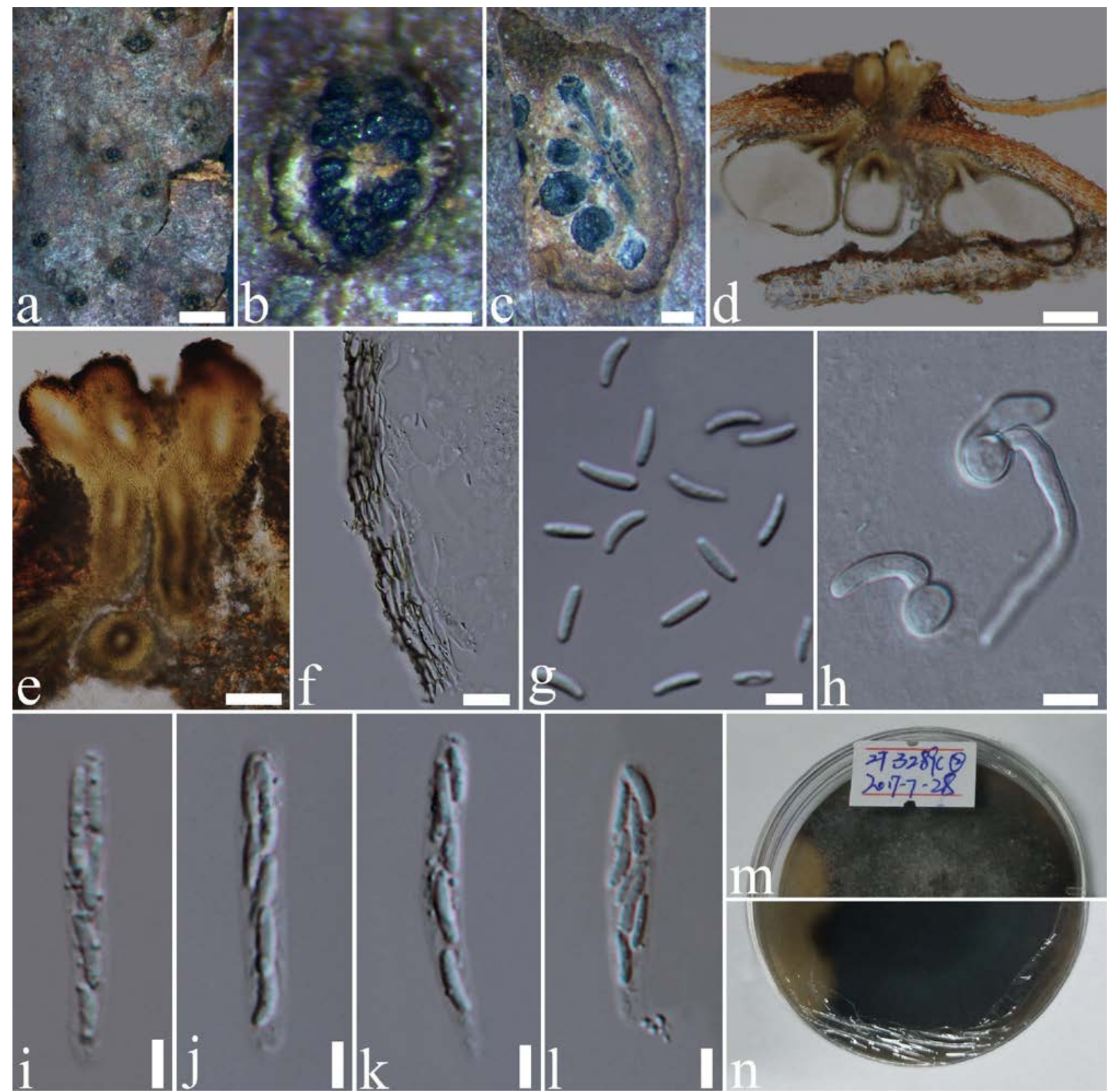

Figure 2 - Cytospora cedri (MFLU 18-1387). a Appearance of stromata on substrate. b Stroma. c Cross section through stroma. d Vertical section through stroma. e Ostiolar canal. f Peridium. g Ascospores. h Germinating ascospore. i-l Asci. m, n Culture characteristic on PDA after 10 days $(\mathrm{m}=$ colony from above, $\mathrm{n}=$ colony from below). Scale bars: $\mathrm{a}=1 \mathrm{~mm}, \mathrm{~b}, \mathrm{c}=200 \mu \mathrm{m}, \mathrm{d}=100$ $\mu \mathrm{m}, \mathrm{e}=50 \mu \mathrm{m}, \mathrm{f}=20 \mu \mathrm{m}, \mathrm{g}, \mathrm{i}-\mathrm{l}=5 \mu \mathrm{m}, \mathrm{h}=10 \mu \mathrm{m}$.

Notes - The phylogenetic result (Fig. 1) shows that our new strain (MFLUCC 18-1203) clusters together with a Cytospora cotini strain (MFLUCC 14-1050, holotype) and they share a sister relationship to Cytospora ampulliformis (MFLUCC 16-0583, holotype), Cytospora ceratosperma (MFLUCC 16-0625) and Cytospora gelida (MFLUCC 16-0634, holotype) with 46\% ML, 60\% MP and 0.80 PP support. Our specimen of C. cotini (MFLU 17-0864) differs from C. ceratosperma by its larger stromata, shorter ostiolar canal (Table 2) and its asci with J-, refractive apical ring (Tibpromma et al. 2017). The taxa of C. ampulliformis, C. cotini and C. gelida were only reported in their asexual morph, and it is impossible to compare with our samples which are sexual morphs (Norphanphoun et al. 2017, Tibpromma et al. 2017). Considering the unresolved phylogenetic result and the incomparable morphology, we compared the single gene regions of ITS, LSU and RPB2 (Table 4) for these taxa, which displayed the highest nucleotides sequence 
similarity between strains MFLUCC 18-1203 and MFLUCC 14-1050. Based on the guidelines of Jeewon \& Hyde (2016), we identify our specimen as C. cotini and provide the first sexual morph description of this species. However, our study indicates that taxonomic revision of $C$. ampulliformis, C. ceratosperma, C. cotini and C. gelida in Cytospora is needed based on type studies and further analyses from other informative genes and with more taxon sampling (Jeewon \& Hyde 2016).

Cytospora diopuiensis Q.J. Shang, K.D. Hyde \& J.K. Liu, sp. nov.

Fig. 4

Index Fungorum number: IF 555502; Facesoffungi number: FoF 05099

Etymology - Names after a famous mountain "Dio Pui” in Mueang Chiang Mai District of Thailand, of where the fungus was collected nearby.

Holotype - MFLU 18-1390

Saprobic on the bark. Sexual morph Stromata 0.8-1.2 mm wide, with the poorly developed interior, solitary to gregarious, immersed, becoming raised to erumpent by the ostiolar canal, dark brown to black, glabrous, circular in shape, arranged with conspicuous, clustered, roundish to cylindrical prominent ostioles. Ascomata (excluding necks) 117-192 $\mu \mathrm{m}$ high, 205-333 $\mu \mathrm{m}$ diam. $(\bar{x}=154 \times 269 \mu \mathrm{m}, \mathrm{n}=15)$, perithecial, immersed in a stroma, brown to dark brown, globose to subglobose, glabrous, individual ostiole with the neck. Ostiolar canal 242-520 $\mu \mathrm{m}$ high, 95-121 $\mu \mathrm{m}$ diam. $(\bar{x}=381 \times 108 \mu \mathrm{m}, \mathrm{n}=10)$, cylindrical, sulcate, periphysate. Peridium $15-25 \mu \mathrm{m}$ wide, composed of two section layers, outer section comprising 3-5 layers, yellow to brown, thickwalled cells, arranged in textura angularis, the inner part comprising 3-4 layers of hyaline cells of textura angularis. Hamathecium composed of 2.2-2.7 $\mu \mathrm{m}$ wide, cylindrical, aseptate, hyaline, paraphyses. Asci (23-)25-31(-34) × (4-)4.5-6(-6.5) $\mu \mathrm{m}(\bar{x}=27.8 \times 5.2 \mu \mathrm{m}, \mathrm{n}=50)$, 8-spored, unitunicate, cylindrical to clavate, sessile, apically rounded to truncate, with a J- apical ring. Ascospores (6.5-)7.5-8.5(-9) $\times(1.2-) 1.5-2.5(-3.6) \mu \mathrm{m}(\bar{x}=8 \times 1.9 \mu \mathrm{m}, \mathrm{n}=75)$, overlapping 1-2seriate, hyaline, oblong to elongate-allantoid, aseptate, smooth-walled. Asexual morph Undetermined.

Culture characteristics - Ascospores germinating on PDA within 12 hrs. Germ tubes produced from all sides. Colonies on PDA reaching $4-5 \mathrm{~cm}$ diam. after 7 days at room temperature, colonies circular to irregular, medium dense, flat or effuse, slightly raised, with edge fimbriate, felt-like, initially white, becoming yellow after 7 days. After 10-15 days, gray to black from above, black from below; not producing pigments in agar.

Material examined - THAILAND, Chiang Mai Province, Mueang Chiang Mai District, on dead wood, 27 July 2016, Qiuju Shang, DP03 (MFLU 18-1390, holotype; KUN-HKAS 99637, isotype), ex-type living culture, MFLUCC 18-1419.

Notes - Cytospora diopuiensis resembles Cytospora thailandica in having the conspicuous, clustered ostioles, sessile asci and elongate-allantoid ascospores (Norphanphoun et al. 2018). However, Cytospora diopuiensis is distinguished from $C$. thailandica by having larger stromata, asci and ascospores (Table 2). Moreover, Cytospora diopuiensis is distinct from C. thailandica in the asci having $\mathrm{J}-$, apical ring, whereas the asci of $C$. thailandica having $\mathrm{J}-$, refractive, apical ring (Norphanphoun et al. 2018). Phylogenetically, the isolate of C. diopuiensis (MFLUCC 18-1419) clusters with the strain Phomopsis theae (GJJM16), with high support (100\% ML, 100\% MP and 1 PP), and they are sister to C. thailandica with moderate support (89\% ML, 85\% MP and 1 PP) (Fig. 1 ). The strain of GJJM16, an endophyte was isolated and given the taxonomic placement as $P$. theae by Jayanthi et al. (2018) and Phomopsis theae (Diaporthe theae) was reported as an asexual morph taxon (Petch 1925, Rossman et al. 2015). However, Jayanthi et al. (2018) did not provide a detailed morphological description and phylogenetic analysis for this isolate to justify its taxonomic identification. Moreover, there is only ITS sequence provided for the strain of GJJM16 in GenBank. We carried out the ITS gene comparison between our isolate (MFLUCC 18-1419) and the strain ("P. theae" GJJM16), and there is no significant difference between them (Table 4), hence they could be identified as same species (Jeewon \& Hyde 2016). Therefore, we introduce them as a new species $C$. diopuiensis. 

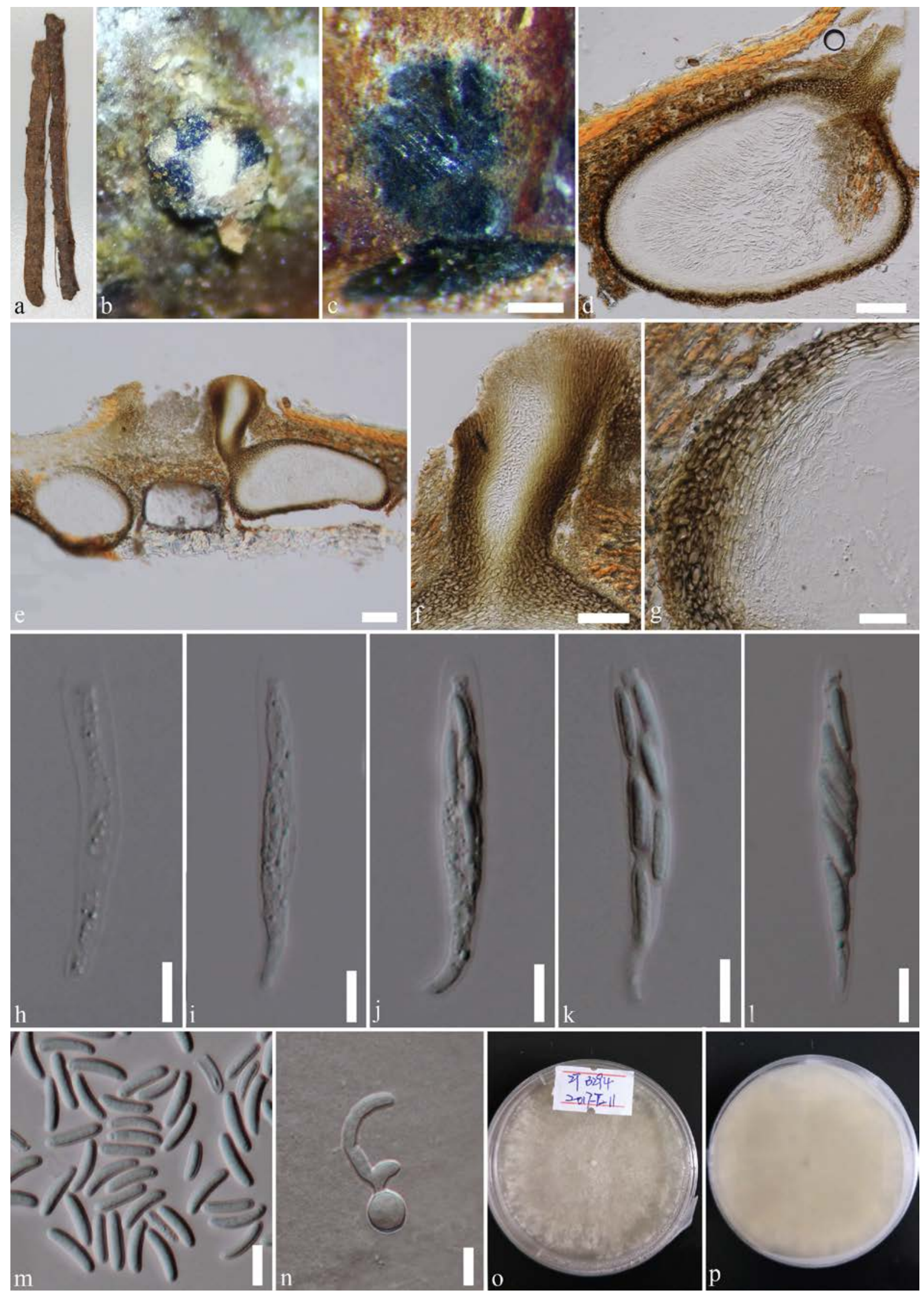

Figure 3 - Cytospora cotini (MFLU 17-0864). a Host substrate. b Stroma. c Cross section through stroma. d Ascoma. e Vertical section through stroma. f Ostiolar canal. g Peridium. h-l Asci. $\mathrm{m}$ Ascospores. $\mathrm{n}$ Germinating ascospore. o, p Culture characteristic on PDA after 10 days (o = colony from above, $\mathrm{p}=$ colony from below). Scale bars: $\mathrm{c}=200 \mu \mathrm{m}, \mathrm{d}, \mathrm{e}=100 \mu \mathrm{m}, \mathrm{f}=50 \mu \mathrm{m}, \mathrm{g}=$ $20 \mu \mathrm{m}, \mathrm{h}-\mathrm{n}=10 \mu \mathrm{m}$. 

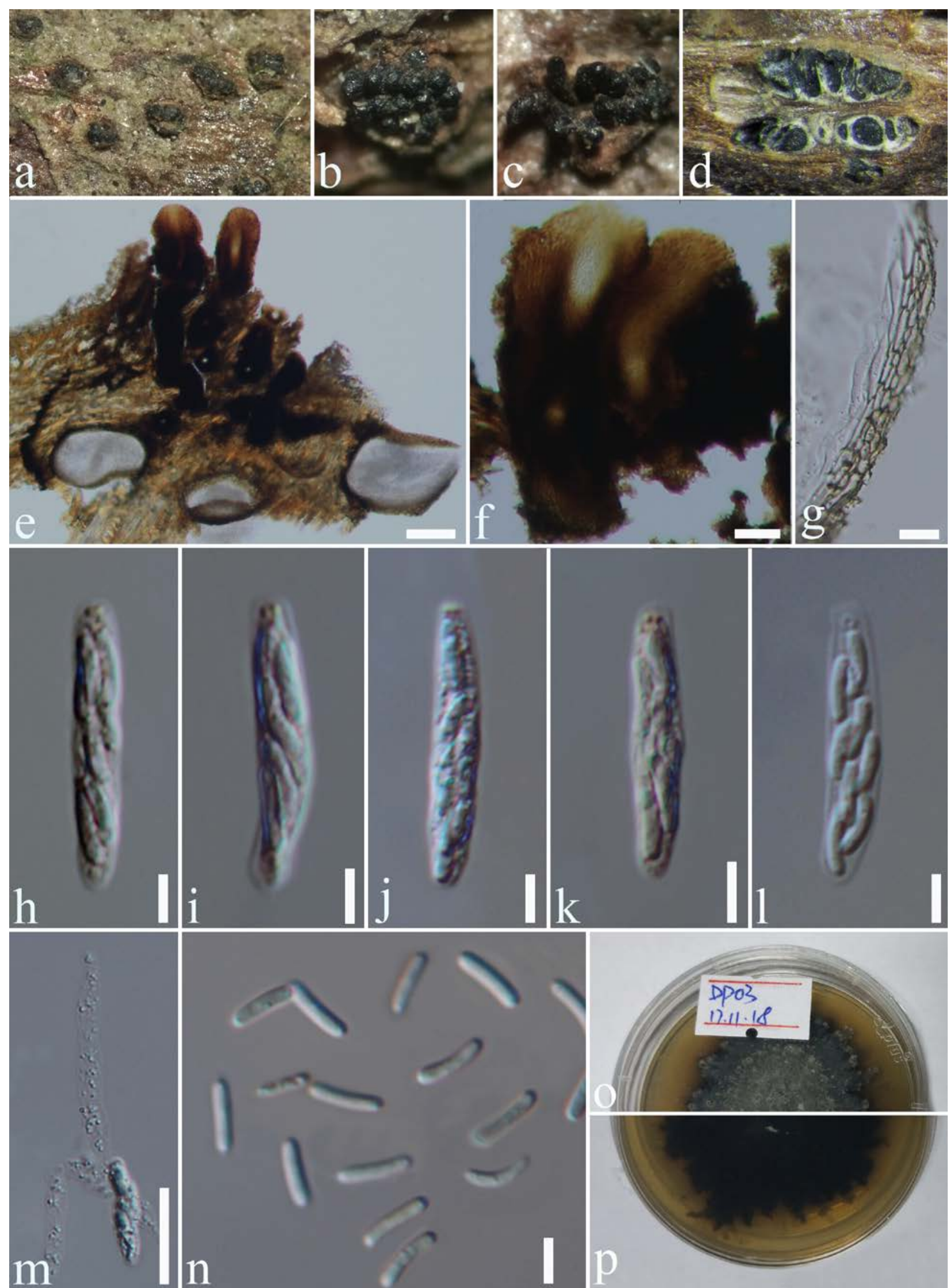

Figure 4 - Cytospora diopuiensis (MFLU 18-1390, holotype). a-c Appearance of stromata on the substrate. d Cross section through stroma. e Vertical section through stroma. f Ostiolar canal. g Peridium. h-l Asci ( $\mathrm{h}-\mathrm{k}=$ stained with Congo red). m Paraphyses. n. Ascospores. o, p Culture characteristic on PDA after 10 days ( $\mathrm{o}=$ colony from above, $\mathrm{p}=$ colony from below). Scale bars: e $=100 \mu \mathrm{m}, \mathrm{f}, \mathrm{m}, \mathrm{n}=20 \mu \mathrm{m}, \mathrm{g}=10 \mu \mathrm{m}, \mathrm{h}-\mathrm{l}=5 \mu \mathrm{m}$. 
Cytospora galegicola Q.J. Shang, E. Camporesi \& K.D. Hyde, sp. nov.

Fig. 5

Index Fungorum number: IF 555503; Facesoffungi number: FoF 05100

Etymology - Names reflect the host, of which the fungus was collected from "Galega officinalis".

Holotype - MFLU 16-2280

Saprobic on the bark. Sexual morph Stromata 0.6-1.3 mm wide, with the poorly developed interior, solitary to gregarious, immersed, becoming raised to erumpent by the ostiolar canal, dark brown to black, glabrous, irregular in shape, arranged with conspicuous, scattered, roundish to cylindrical prominent ostioles. Ascomata (excluding necks) 170-275 $\mu \mathrm{m}$ high, 210-390 $\mu \mathrm{m}$ diam. $(\bar{x}=223 \times 300 \mu \mathrm{m}, \mathrm{n}=20)$, perithecial, immersed in a stroma, yellow to brown, globose to subglobose, glabrous, individual ostiole with the neck. Ostiolar canal 170-210 $\mu \mathrm{m}$ high, 40-135 $\mu \mathrm{m}$ diam. $(\bar{x}=189 \times 44 \mu \mathrm{m}, \mathrm{n}=18)$, cylindrical, sulcate, concentrated, periphysate. Peridium 23$34 \mu \mathrm{m}$ wide, composed of two section layers, outer section comprising 3-6 layers, of relatively small, yellow, thick-walled cells, arranged in textura angularis, inner part comprising 3-4 layers of hyaline cells of textura angularis. Hamathecium composed of 5-6 $\mu \mathrm{m}$ wide, dense, cylindrical, septate, hyaline, paraphyses. Asci (33-)38-45(-49) $\times(4.5-) 5.5-6.5(-7.5) \mu \mathrm{m}(\bar{x}=41 \times 6 \mu \mathrm{m}, \mathrm{n}=$ 45), 8-spored, unitunicate, clavate, with short stalks, apically rounded to truncate, with a J- apical ring. Ascospores (5.8-)6.8-10(-12.5) $\times(1.5-) 2-3(-4) \mu \mathrm{m}(\bar{x}=8.4 \times 2.5 \mu \mathrm{m}, \mathrm{n}=75)$, overlapping 1-2-seriate, hyaline, oblong to allantoid, aseptate, smooth-walled. Asexual morph Coelomycetous. Conidiomata 430-589 $\mu \mathrm{m}$, pycnidial, with multi-loculate, appearing as brown to black, watery, rounded, conidial masses, superficial, solitary or aggregated, subglobose, shiny, with white to brown mycelium covering the surface. Pycnidial walls 13-21 $\mu \mathrm{m}$ wide, comprising several layers of hyaline to brown, compressed hyphae, arranged in a textura intricata. Conidiogenous cells (7.2)9.5-19.5(-23) $\times(1.5-) 1.8-3.2(-4)(\bar{x}=14.4 \times 2.5 \mu \mathrm{m}, \mathrm{n}=15)$, cylindrical to clavate, holoblastic, straight or curved. Conidia (4.8-)5-6.8(-10.7) $\times(0.8-) 1-1.5(-2.0) \bar{x}=7.6 \times 1.3 \mu \mathrm{m}, \mathrm{n}=150)$, hyaline, allantoid, some with strongly curved ends, unicellular, smooth-walled.

Culture characteristics - Ascospores germinating on PDA within 24 hrs. Germ tubes produced from all sides. Colonies on PDA reaching 5-5.5 cm diam. after 15 days at room temperature, colonies circular to irregular, medium dense, flat or effuse, slightly raised, with edge fimbriate, fluffy to fairy fluffy, white from above, light yellow from below; not producing pigments in agar.

Material examined - Italy, Fiumicello, Premilcuore (Province of Forlì-Cesena [FC]), on dead aerial stem of Galega officinalis, 27 July 2016, E. Camporesi, IT 3045 (MFLU 16-2280, holotype; KUN-HKAS 100884, isotype), ex-type living culture, MFLUCC 18-1199.

Notes - The phylogenetic inference obtained in this study (Fig. 1) shows that the new taxon Cytospora galegicola (MFLUCC 18-1199) forms a distinct lineage close to Cytospora coenobitica (CBS 283.74) and Cytospora subclypeata (CBS 117.67) with high support (ITS, 96\% ML, 80\% MP and $1.00 \mathrm{PP}$ ). Morphologically, Cytospora galegicola has larger conidia than C. coenobitica and $C$. subclypeata (Saccardo 1884, 1986, Table 3). Therefore, Cytospora galegicola is described as a new species and the description and illustration of the holomorph are provided herein.

Cytospora pingbianensis Q.J. Shang, K.D. Hyde \& J.K. Liu, sp. nov.

Fig. 6

Index Fungorum number: IF 555514; Facesoffungi number: FoF 05107

Etymology - The species epithet "pingbianensis" refers to the town Ping bian in China where the fungus was collected.

Holotype - KUN-HKAS 102161

Saprobic on the bark. Sexual morph Stromata 880-1524 $\mu$ m wide, with the poorly developed interior, solitary to gregarious, immersed, becoming raised to erumpent by the ostiolar canal, dark brown to black, glabrous, circular in shape, arranged with conspicuous, clustered, roundish to cylindrical prominent ostioles. Ascomata (excluding necks) 142-248 $\mu \mathrm{m}$ high, 113-245 $\mu \mathrm{m}$ diam. $(\bar{x}=195 \times 180 \mu \mathrm{m}, \mathrm{n}=50)$, perithecial, immersed in a stroma, brown to dark brown, globose to subglobose, glabrous, individual ostiole with the neck. Ostiolar canal 185-722 $\mu \mathrm{m}$ high, 27-66 $\mu \mathrm{m}$ 
diam. $(\bar{x}=453 \times 47 \mu \mathrm{m}, \mathrm{n}=10)$, cylindrical, sulcate, periphysate. Peridium 14-24 $\mu \mathrm{m}$ wide, composed of two section layers, outer section comprising 3-5 layers, of relatively small, brown to dark brown, thick-walled cells, arranged in textura angularis, the inner part comprising $3-5$ layers of hyaline cells of textura angularis. Hamathecium comprising only asci. Asci (25-)27-30(-33) $\times$ (3.5-)4-5(-6) $\mu \mathrm{m}(\bar{x}=28 \times 4.7 \mu \mathrm{m}, \mathrm{n}=70), 8$-spored, unitunicate, clavate, sessile, apically rounded to truncate, with a J- apical ring. Ascospores (4.6-)5.8-6.7(-7.5) × (1-)1.5-2(-2.5) $\mu \mathrm{m}(\bar{x}$ $=6.2 \times 1.7 \mu \mathrm{m}, \mathrm{n}=210)$, overlapping 1-2-seriate, hyaline, allantoid, aseptate, smooth-walled. Asexual morph Undetermined.

Culture characteristics - Ascospores germinating on PDA within 12 hrs. Germ tubes produced from all sides. Colonies on PDA reaching 2.5-5.5 cm diam. after 5 days at room temperature, colonies circular to irregular, medium dense, flat or effuse, slightly raised, with edge fimbriate, fluffy to fairy fluffy, initially white to yellow from above, yellow from below; After 10 days, yellow to brown from above, brown to dark brown from below; not producing pigments in agar.

Material examined - CHINA, Yunnan Province, Pingbian, on a dead branch of undetermined wood, 26 September 2017, Qiuju Shang, PB45 (KUN-HKAS 102161, holotype; MFLU 18-1389, isotype), ex-type living culture, MFLUCC 18-1204.

Notes - The phylogenetic result (Fig. 1) shows that our strain of Cytopora pingbianensis (MFLUCC 18-1204) forms a distinct lineage and is close to Cytopora platycladi (CFCC 50504, CFCC 50505) with the high support (100\% ML, 99\% MP and 1 PP). These taxa form a sister clade to Cytopora lumnitzericola with moderate support (89\% ML, 75\% MP and 0.99 PP). Cytospora platycladi and $C$. lumnitzericola were reported as asexual morph taxa associated with canker disease (Norphanphoun et al. 2018, Fan et al. 2020), while our taxon is only reported as a sexual morph. In this study, C. pingbianensis can be recognized as a phylogenetically distinct species (Fig. 1 ), and it is introduced as new species with detailed description and illustration of the sexual morph.

Cytospora predappioensis Q.J. Shang, Norphanph., Camporesi \& K.D. Hyde, Mycosphere 9(2): 376 (2018)

Figs 7-9

Index Fungorum number: IF554083; Facesoffungi number: FoF03936

Saprobic on the bark. Sexual morph Stromata 647-2225 $\mu$ m wide, with the poorly developed interior, solitary to gregarious, immersed, becoming raised to erumpent the bark by the ostiolar canal, dark brown to black, glabrous, circular to irregular in shape, arranged with conspicuous, clustered, roundish to cylindrical prominent ostioles. Ascomata (excluding necks) 209-413 $\mu \mathrm{m}$ high, $194-360 \mu \mathrm{m}$ diam. $(\bar{x}=300 \times 277 \mu \mathrm{m}, \mathrm{n}=10)$, perithecial, immersed in a stroma, dark brown to brown, globose to subglobose, glabrous, individual ostiole with the neck. Ostiolar canal 434-1185 $\mu \mathrm{m}$ high, 104-145 $\mu \mathrm{m}$ diam. $(\bar{x}=725 \times 117 \mu \mathrm{m}, \mathrm{n}=15)$, cylindrical, sulcate, periphysate. Peridium 23-40 $\mu \mathrm{m}$ wide, composed of two section layers, outer section comprising 5-8 layers, of relatively small, brown to dark brown, thick-walled cells, arranged in textura angularis, the inner part comprising 2-3 layers of hyaline cells of textura angularis. Hamathecium comprising only asci. Asci (23-)25-38(-50) × (3.5-)4-6.5(-8.5) $\mu \mathrm{m}(\bar{x}=32 \times 5.4 \mu \mathrm{m}, \mathrm{n}=60), 8$ spored, unitunicate, clavate, sessile, apically rounded to truncate, with a J- apical ring. Ascospores (6.5-)7-10 (-12) × (1.5-)1.7-3(-3.5) $\mu \mathrm{m}(\bar{x}=8.4 \times 2.2 \mu \mathrm{m}, \mathrm{n}=120)$, overlapping 1-3-seriate, hyaline, allantoid, aseptate, smooth-walled. Asexual morph Coelomycetous. Conidiomata 540-665 $\mu \mathrm{m}$, pycnidial, with 2-4-loculate, appearing as beige-white to brown, watery, rounded, conidial masses, superficial, solitary or aggregated, globose, shiny, with white to brown mycelium covering the surface. Pycnidial walls 13-21 $\mu \mathrm{m}$ wide, comprising several layers of brown, compressed hyphae, arranged in a textura intricata. Conidiogenous cells 8.5-10.5(-11) $\times 1.5-2.7(-3)(\bar{x}=9.7$ $\times 2 \mu \mathrm{m}, \mathrm{n}=5)$, cylindrical to clavate, holoblastic, straight. Conidia $(4.5-) 5-6.5(-8) \times(0.8-) 1-1.5(-$ 1.8) $(\bar{x}=6 \times 1.4 \mu \mathrm{m}, \mathrm{n}=75)$, hyaline, allantoid, unicellular, smooth-walled. 

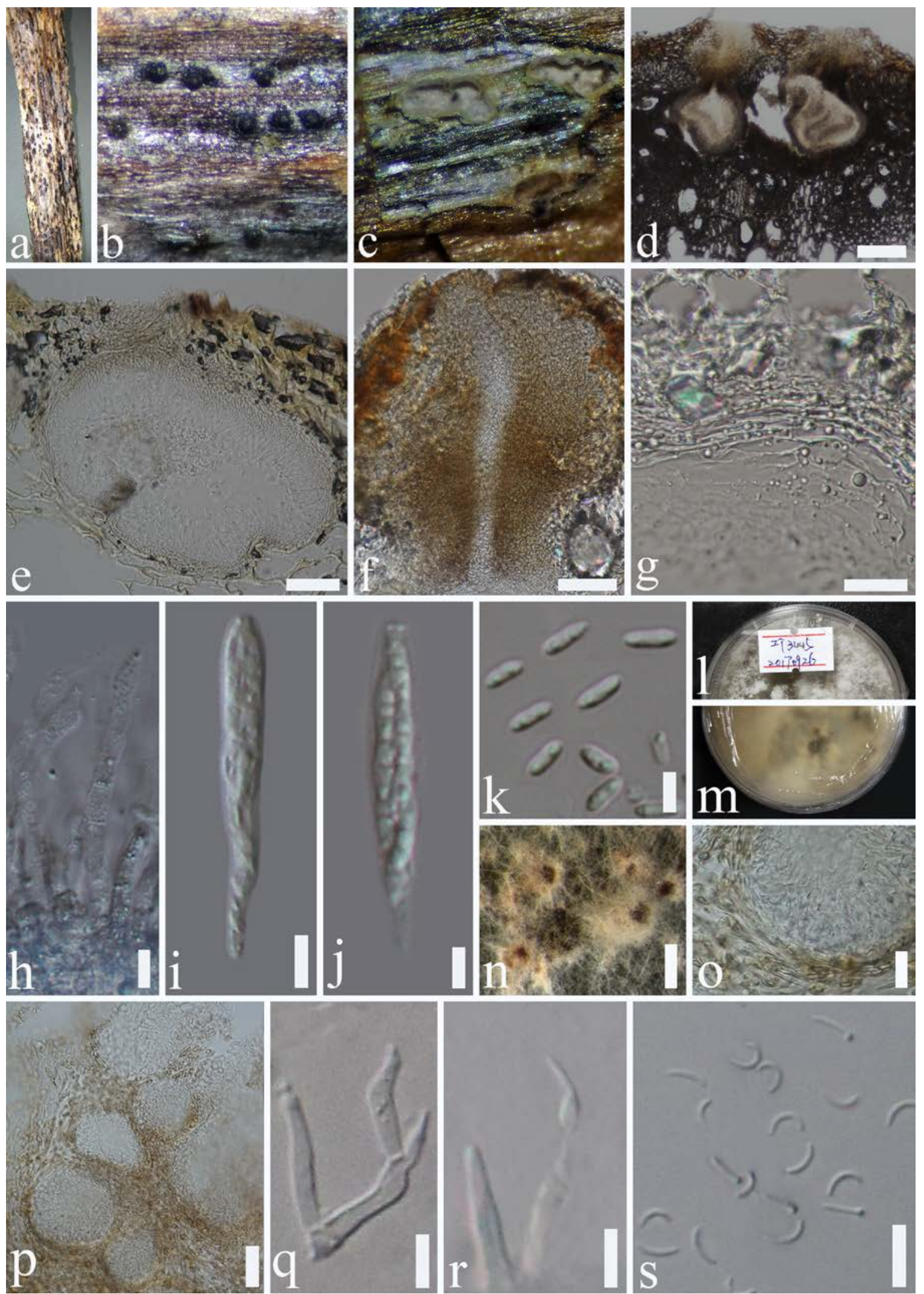

Figure 5 - Cytospora galegaicola (MFLU 16-2280, holotype). a Host substrate. b Appearance of stromata on the substrate. c Cross section through stroma. d Vertical section through stroma. e Ascoma. f Ostiolar canal. g Peridium. h Paraphyses. i, j Asci. k Ascospores. l, m Culture characteristic on PDA after 10 days $(\mathrm{l}=$ colony from above, $\mathrm{m}=$ colony from below $)$. $\mathrm{n}$ Conidiomata on PDA. o. Peridium. p. Section of conidioma. q, r. Conidia attached to conidiogenous cells. s. Conidia. Scale bars: $\mathrm{d}=200 \mu \mathrm{m}$, e, $\mathrm{f}=100 \mu \mathrm{m}, \mathrm{g}=50 \mu \mathrm{m}, \mathrm{h}, \mathrm{o}, \mathrm{p}=20 \mu \mathrm{m}$, $\mathrm{i}-\mathrm{k}, \mathrm{s}=10 \mu \mathrm{m}, \mathrm{q}, \mathrm{r}=5 \mu \mathrm{m}$. 

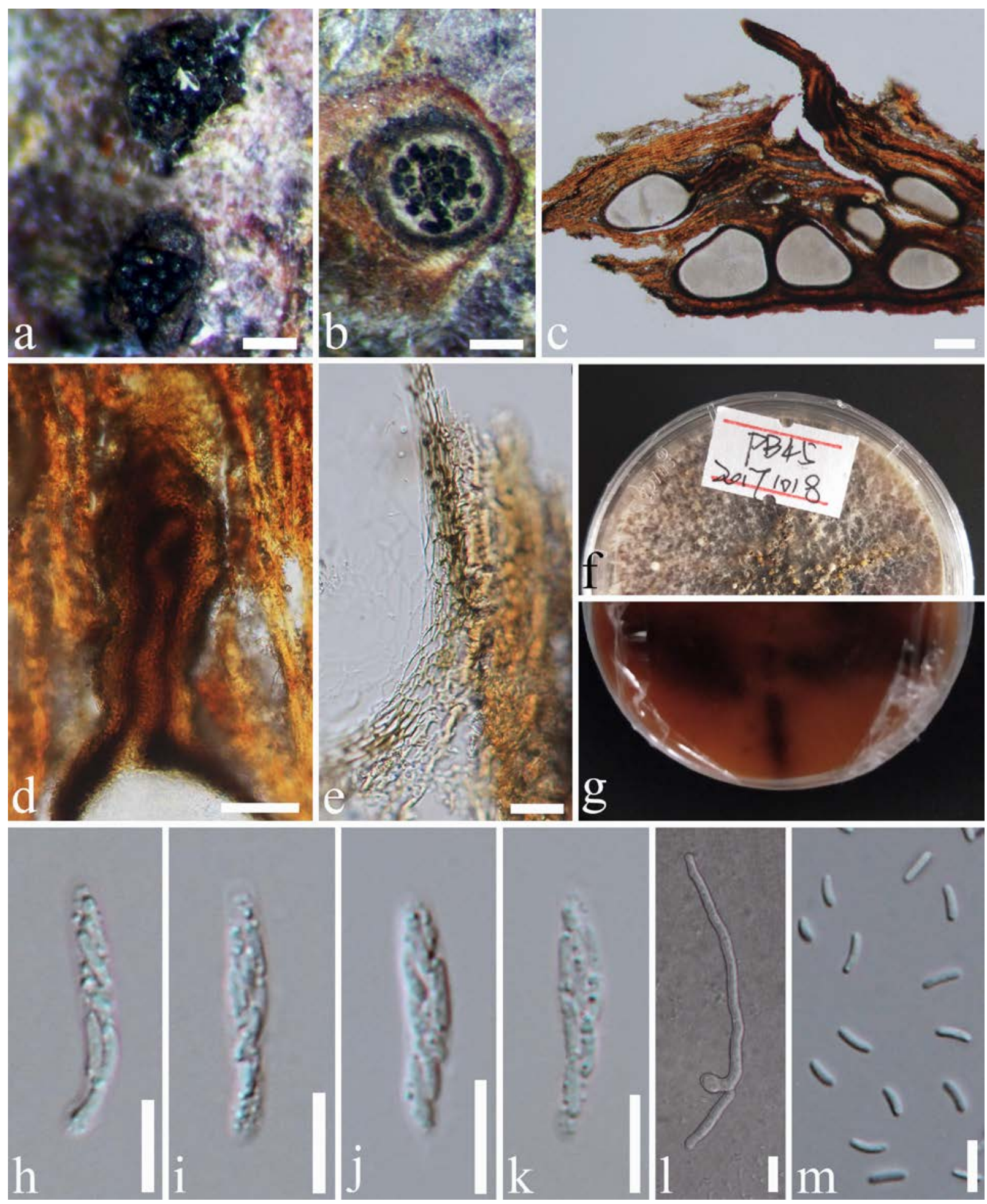

Figure 6 - Cytospora pingbianensis (KUN-HKAS 102161, holotype). a Stromata. b Cross section through stroma. c Vertical section through stroma. d Ostiolar canal. e Peridium. f, g Culture characteristic on PDA ( $\mathrm{f}=$ colony from above, $\mathrm{g}=$ colony from below). $\mathrm{h}-\mathrm{k}$ Asci. $\mathrm{l}$ Germinating ascospore. $\mathrm{m}$ Ascospores. Scale bars: $\mathrm{a}, \mathrm{b}=200 \mu \mathrm{m}, \mathrm{c}=100 \mu \mathrm{m}, \mathrm{d}=50 \mu \mathrm{m}, \mathrm{e}, \mathrm{l}=20 \mu \mathrm{m}, \mathrm{h}-\mathrm{k}, \mathrm{m}$ $=10 \mu \mathrm{m}$.

Culture characteristics - Ascospores germinating on PDA within 24 hrs. Germ tubes produced from all sides. Colonies on PDA reaching and 5-5.5 cm diam. after 15 days at room temperature, colonies circular to irregular, medium dense, flat or effuse, slightly raised, with edge fimbriate, fluffy to fairy fluffy, white from above, white to yellow from below after 5 days, dark brown from above, brown to dark brown from below after 15 days; not producing pigments in agar. 

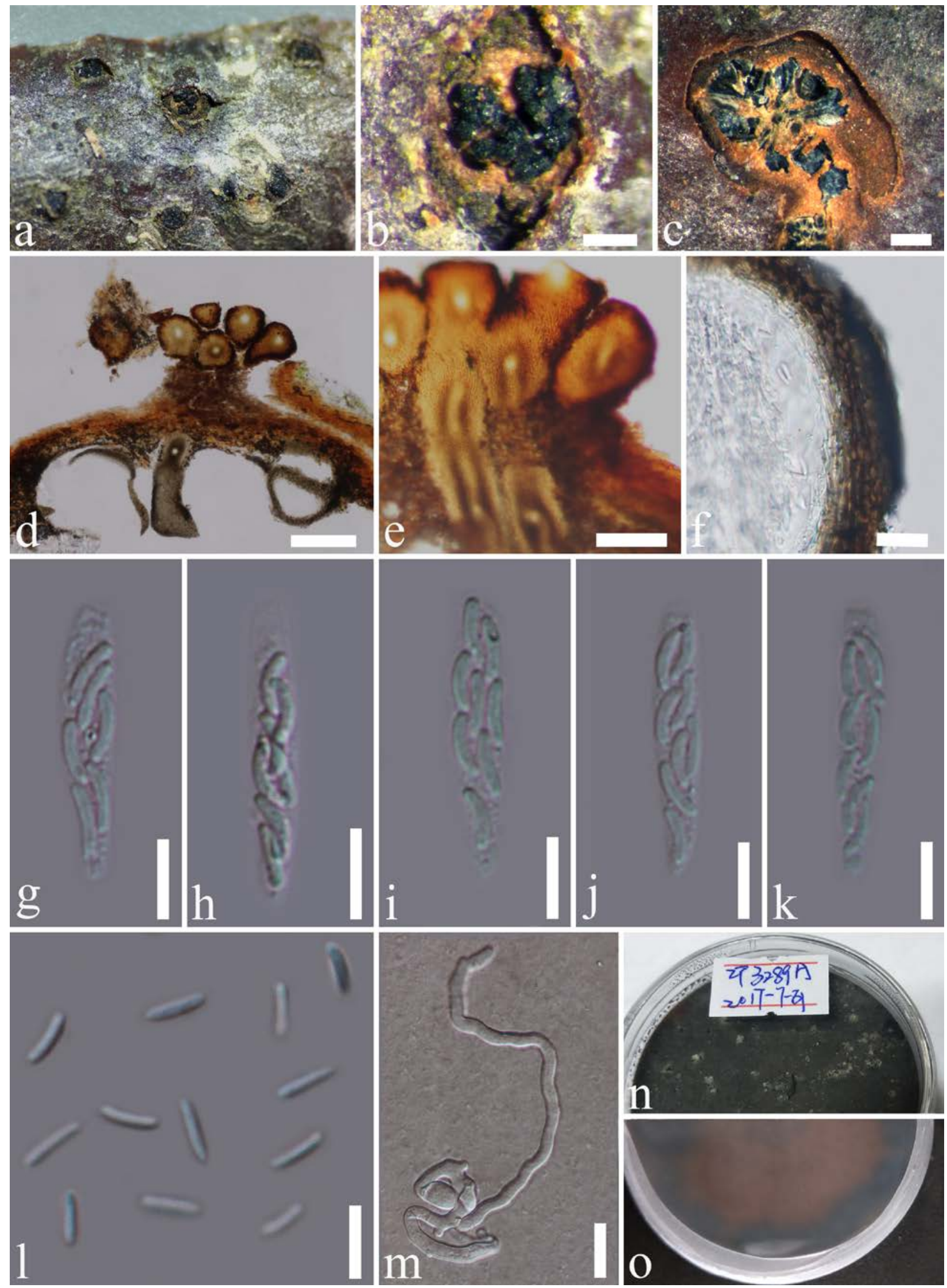

Figure 7 - Cytospora predappioensis (MFLU 17-0846, MFLU 17-0836). a Appearance of stromata on the substrate. b Stroma. c Cross section through stroma. d Vertical section through stroma. e Ostiolar canal. f Peridium. g-k Asci. l Ascospores. m Germinating ascospore. n, o Culture characteristic on PDA after 10 days ( $\mathrm{n}=$ colony from above, $\mathrm{o}=$ colony from below). Scale bars: $\mathrm{c}-$ $\mathrm{d}=200 \mu \mathrm{m}, \mathrm{e}=100 \mu \mathrm{m}, \mathrm{g}-\mathrm{l}=10 \mu \mathrm{m}, \mathrm{m}=20 \mu \mathrm{m}$. 


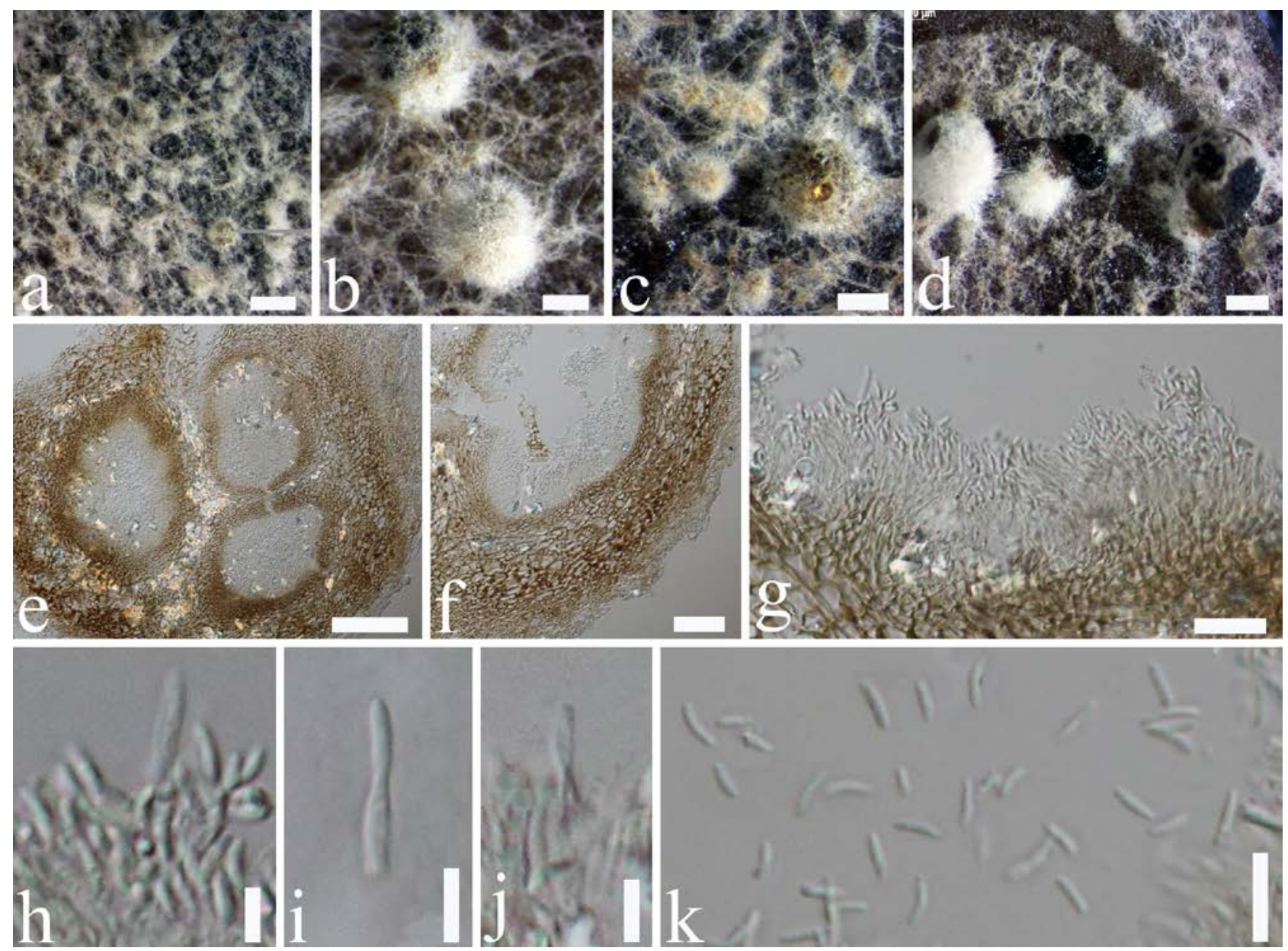

Figure 8 - Cytospora predappioensis (MFLUCC 18-1202). a Culture surface on PDA. b- $d$ Conidiomata on PDA. e Section of the conidioma. f Peridium. g-j Conidia attached to conidiogenous cells. $\mathrm{k}$ Conidia. Scale bars: $\mathrm{a}=1 \mathrm{~mm}, \mathrm{~b}-\mathrm{c}=500 \mu \mathrm{m}, \mathrm{e}=100 \mu \mathrm{m}, \mathrm{f}=50 \mu \mathrm{m}, \mathrm{g}=$ $20 \mu \mathrm{m}, \mathrm{h}, \mathrm{j}=5 \mu \mathrm{m}, \mathrm{i}, \mathrm{k}=10 \mu \mathrm{m}$.

Materials examined - ITALY, near Predappio (Province of Forlì-Cesena [FC]), on a dead land branch of Ostrya carpinifolia, 20 March 2017, E. Camporesi, IT 3289A (MFLU 17-0846, KUN-HKAS 100915), living culture, MFLUCC 18-1202. ITALY, Camposonaldo, Santa Sofia (Province of Forlì-Cesena [FC]) Province, on a dead land branch of O. carpinifolia, 17 March 2017, E. Camporesi, IT 3289 (MFLU 17-0836, KUN-HKAS 102162). CHINA, Yunnan Province, Kunming, on a dead land branch of Cupressus sp., 29 March 2017, Qiuju Shang, SSHJ01 (MFLU 18-1388, KUN-HKAS 100951), living culture, MFLUCC 18-1205.

Notes - The phylogenetic result (Fig. 1) shows that the newly obtained isolates (MFLUCC 18-1202 and MFLUCC 18-1205) clustered together with taxa of Cytospora ceratospermopsis (CFCC 89626 and CFCC 89627), Cytospora predappioensis (MFLUCC 17-2458, MFLUCC 170327) and Cytospora sacculus (CFCC 89624) and can be identified as C. predappioensis. To confirm this identification, the single gene comparison of ITS, LSU and ACT gene regions was carried out between MFLUCC 18-1202, MFLUCC 18-1205 and MFLUCC 17-2458 (the ex-type of C. predappioensis), the result (Table 4) showed that there is no significant difference in nucleotides of ITS, LSU, and ACT gene. In addition, our new collections are morphologically identical to $C$. predappioensis except their longer ostiolar canals (Table 2, Hyde et al. 2018). Therefore, we conservatively identify our specimen as $C$. predappioensis and speculate that the phylogeny of this taxon is complex, and provide the holomorph description from a different host (MFLU 17-0836, MFLU 17-0846, Ostrya carpinifolia vs. MFLU 17-0323, Platanus hybrida, holotype; Figs 7, 8) and a new record (MFLU 18-1388, Cupressus sp., Fig. 9) from China (Hyde et al. 2018). 

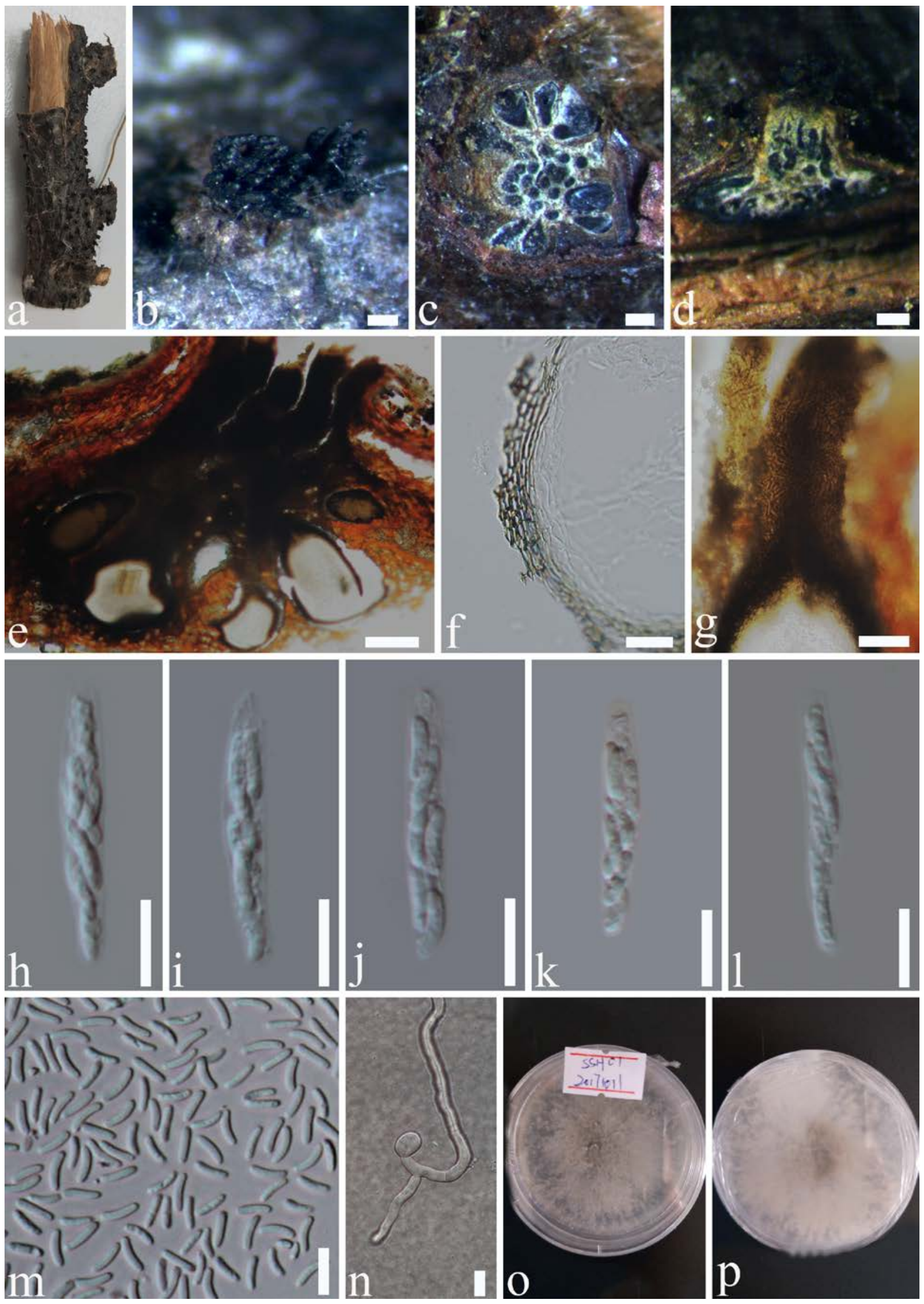

Figure 9 - Cytospora predappioensis (MFLU 18-1388). a Host substrate. b Stroma. c Cross section through stroma. d, e Vertical section through stroma. f Peridium. g Ostiolar canal. h-l Asci. m. Ascospores. $n$ Germinating ascospore. o, p Culture characteristic on PDA (o = colony from above, $\mathrm{p}=$ colony from below). Scale bars: $\mathrm{b}-\mathrm{e}=200 \mu \mathrm{m}, \mathrm{f}, \mathrm{n}=20 \mu \mathrm{m}, \mathrm{g}-\mathrm{m}=10 \mu \mathrm{m}$. 
Index Fungorum number: IF 554078; Facesoffungi number: FoF04097

Saprobic on the bark. Sexual morph Stromata 622-908 $\mu \mathrm{m}$ wide, with the poorly developed interior, solitary to gregarious, immersed, becoming raised to erumpent the bark by the ostiolar canal, dark brown to black, glabrous, circular in shape, arranged with conspicuous, roundish to cylindrical prominent ostioles. Ascomata (excluding necks) 187-270 $\mu \mathrm{m}$ high, 159-289 $\mu \mathrm{m}$ diam. $(\bar{x}=229 \times 224 \mu \mathrm{m}, \mathrm{n}=15)$, perithecial, immersed in a stroma, dark brown to brown, globose to subglobose, glabrous, individual ostiole with the neck. Ostiolar canal 215-250 $\mu \mathrm{m}$ high, 57-122 $\mu \mathrm{m}$ diam., cylindrical, sulcate, periphysate. Peridium 29-48 $\mu \mathrm{m}$ wide, composed of two section layers, outer section comprising 2-5 layers, of relatively small, brown to dark brown, thick-walled cells, arranged in textura angularis, the inner part comprising 2-3 layers of hyaline cells of textura angularis. Hamathecium composed of 6-9 $\mu \mathrm{m}$ wide, dense, cylindrical, septate, hyaline, paraphyses. Asci (45-)55-68(-78) × (7.5-)8.5-10.5(-12) $\mu \mathrm{m}(\bar{x}=62 \times 9.5 \mu \mathrm{m}, \mathrm{n}=50), 8$-spored, unitunicate, clavate, with short stalks, apically rounded to truncate, with a J- apical ring. Ascospores (9.5-)10.5-13.5(-15.5) $\times(3-) 3-4.5(-5) \mu \mathrm{m}(\bar{x}=12 \times 3.7 \mu \mathrm{m}, \mathrm{n}=80)$, overlapping 12-seriate, hyaline, allantoid, aseptate, smooth-walled. Asexual morph Coelomycetous. Conidiomata 259-535 $\mu \mathrm{m}$, pycnidial, appearing as brown to black, watery, rounded, conidial masses, superficial, solitary or aggregated, subglobose, shiny, with white to brown mycelium covering the surface. Pycnidial walls 23-34 $\mu \mathrm{m}$ wide, comprising several layers of brown to dark brown, compressed hyphae, arranged in a textura angularis. Conidiogenous cells (6-)6.5-11(-13) $\times(1-) 1.5-2.5(-3)(\bar{x}$ $=8.7 \times 2 \mu \mathrm{m}, \mathrm{n}=15)$, cylindrical to clavate, holoblastic, straight or curved. Conidia (4-)5-6.8(8.2 $) \times(0.8-) 1-1.5(-2)(\bar{x}=6 \times 1.2 \mu \mathrm{m}, \mathrm{n}=130)$, hyaline, allantoid, slightly curved ends, unicellular, smooth-walled.

Culture characteristics - Ascospores germinating on PDA within 24 hrs. Germ tubes produced from all sides. Colonies on PDA reaching 5-5.5 cm diam. after 5 days at room temperature, colonies circular to irregular, medium dense, flat or effuse, slightly raised, with edge fimbriate, initially fluffy to fairy fluffy, white from above, light yellow to brown from below; After 10 days, white to brown from above, brown to dark brown from below; not producing pigments in agar.

Material examined - Italy, Predappio Alta, Predappio (Province of Forlì-Cesena [FC]), on a dead land branch of Ostrya carpinifolia, 22 November 2016, E. Camporesi, IT 3162 (MFLU 162900, KUN-HKAS S100888), living culture, MFLUCC 18-1200.

Notes - The phylogenetic result (Fig. 1) shows that our strain MFLUCC 18-1200 clusters together with Cytospora prunicola (MFLU 17-0995) with 54\% ML, 84\% MP and 0.82 PP support and they share the sister relationship to Cytospora gutnerae (214) and Cytospora terebinthi (227). The conidia of our strain (MFLUCC 18-1200), on PDA, are similar in size to C. prunicola and smaller in size than C. gutnerae and C. terebinthi (Table 3). Therefore, the collection in the present study is identified as $C$. prunicola and the first sexual morph description of this species is provided here.

Cytospora pubescentis Q.J. Shang, E. Camporesi \& K.D. Hyde, sp. nov.

Figs $12-13$ Index Fungorum number: IF 555505; Facesoffungi number: FoF 05102

Etymology - Names reflect the host, of which the fungus was isolated from "Quercus pubescens".

Holotype - MFLU 17-0727

Saprobic on the bark. Sexual morph Stromata 943-1461 $\mu$ m wide, with the poorly developed interior, solitary to gregarious, immersed, becoming raised to erumpent the bark by the ostiolar canal, dark brown to black, glabrous, circular to irregular in shape, arranged with conspicuous, clustered, roundish to cylindrical prominent ostioles. Ascomata (excluding necks) 183-333 $\mu \mathrm{m}$ high, 158-259 $\mu \mathrm{m}$ diam. $(\bar{x}=258 \times 209 \mu \mathrm{m}, \mathrm{n}=18)$, perithecial, immersed in a stroma, brown to 
dark brown, globose to subglobose, glabrous, individual ostiole with the neck. Ostiolar canal 300$460 \mu \mathrm{m}$ high, $65-103 \mu \mathrm{m}$ diam. $(\bar{x}=382 \times 84 \mu \mathrm{m}, \mathrm{n}=15)$, cylindrical, sulcate, periphysate.

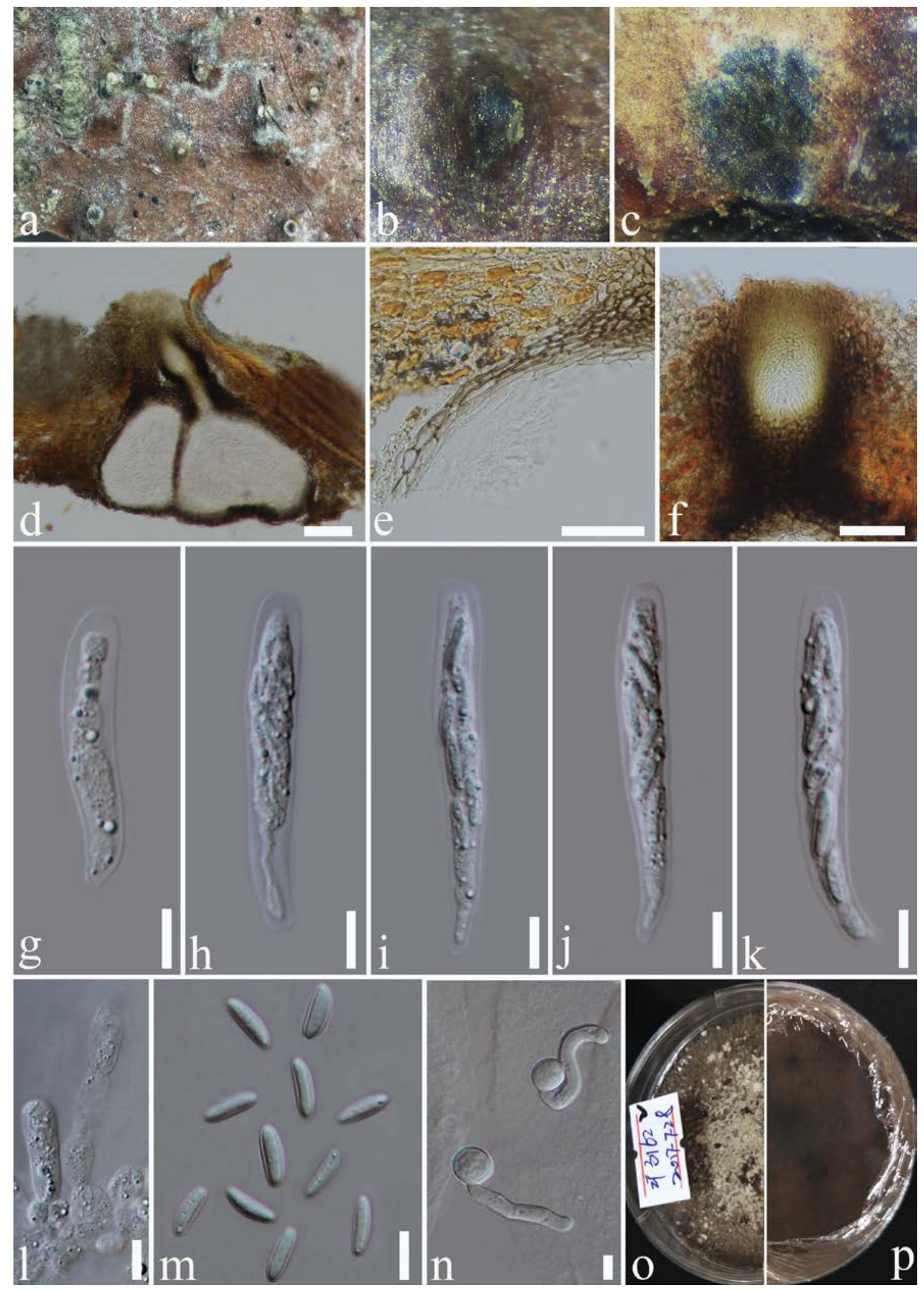

Figure 10 - Cytospora prunicola (MFLU 16-2900). a, b Appearance of stromata on the substrate. c Cross section through stroma. d Vertical section through stroma. e Peridium. f Ostiolar canal. g-k Asci. l Paraphyses. m Ascospores. n Germinating ascospores. o, p Culture characteristic on PDA (o = colony from above, $\mathrm{p}=$ colony from below). Scale bars: $\mathrm{d}=100 \mu \mathrm{m}, \mathrm{e}, \mathrm{f}=50 \mu \mathrm{m}, \mathrm{g}-\mathrm{n}=$ $10 \mu \mathrm{m}$. 

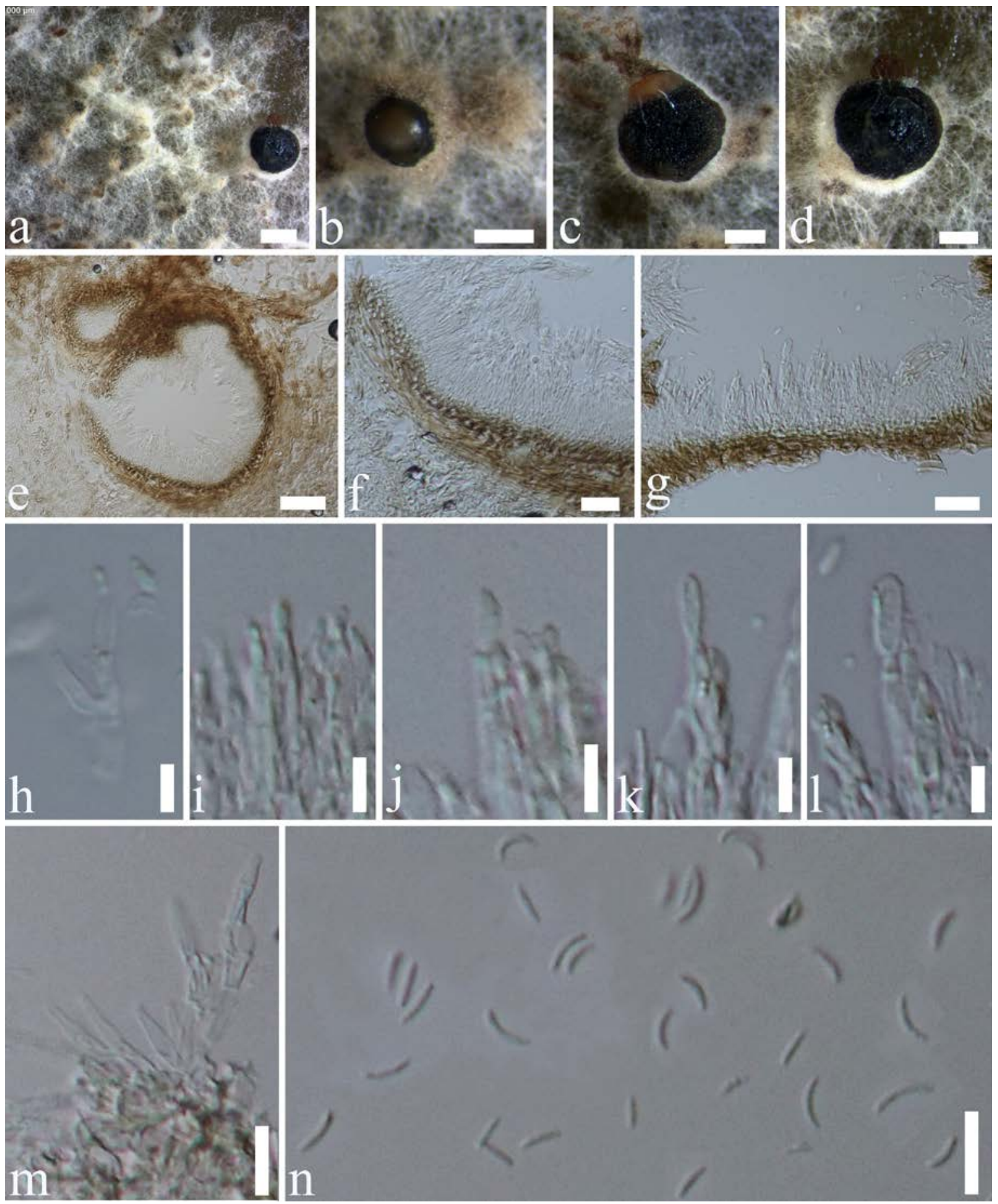

Figure 11 - Cytospora prunicola (MFLUCC 18-1200). a Culture surface on PDA. b-d Conidiomata on PDA. e Section of the conidioma. f Peridium. g-l Conidia attached to conidiogenous cells. $\mathrm{m}$ Conidiogenous cells. $\mathrm{n}$ Conidia. Scale bars: $\mathrm{a}=1 \mathrm{~mm}, \mathrm{~b}-\mathrm{c}=500 \mu \mathrm{m}, \mathrm{e}=$ $50 \mu \mathrm{m}, \mathrm{f}, \mathrm{g}=20 \mu \mathrm{m}, \mathrm{h}-\mathrm{l}=5 \mu \mathrm{m}, \mathrm{m}, \mathrm{n}=10 \mu \mathrm{m}$.

Peridium 22-38 $\mu \mathrm{m}$ wide, composed of two section layers, outer section comprising 2-3 layers, brown to dark brown, thick-walled cells, arranged in textura angularis, inner part comprising 3-4 layers of hyaline cells of textura angularis. Hamathecium comprising only asci. Asci (28-)32-37(-40) × (4-)5-6(-6.8) $\mu \mathrm{m}(\bar{x}=34 \times 5.5 \mu \mathrm{m}, \mathrm{n}=80), 8$-spored, unitunicate, cylindrical to clavate, sessile, apically rounded to truncate, with a J- apical ring. Ascospores (5.7)6.8-8.7(-10.3) $\times(1.5-) 1.9-2.7(-3.4) \mu \mathrm{m}(\bar{x}=7.8 \times 2.3 \mu \mathrm{m}, \mathrm{n}=110)$, overlapping 1-2-seriate, hyaline, allantoid, aseptate, smooth-walled. Asexual morph Coelomycetous. Conidiomata pycnidial, with 2-4-loculate, appearing as brown to black, watery, rounded, conidial masses, 
superficial, solitary or aggregated, globose, with beige-white to brown mycelium covering the surface. Pycnidial walls 60-83 $\mu \mathrm{m}$ wide, comprising several layers of brown, compressed hyphae, arranged in a textura intricata. Conidiogenous cells (7.5-) 9-22 (-28.5) $\times(2.0-) 2.2-4.5(-6)(\bar{x}=$ $15.5 \times 3.3 \mu \mathrm{m}, \mathrm{n}=10)$, clavate to ampulliform, holoblastic, straight. Conidia $(2.7-) 5.8-7.5(-8.5) \times$ (1-)1.3-1.6(-1.8) $(\bar{x}=7.4 \times 1.5 \mu \mathrm{m}, \mathrm{n}=85)$, hyaline, allantoid, unicellular, smooth-walled.
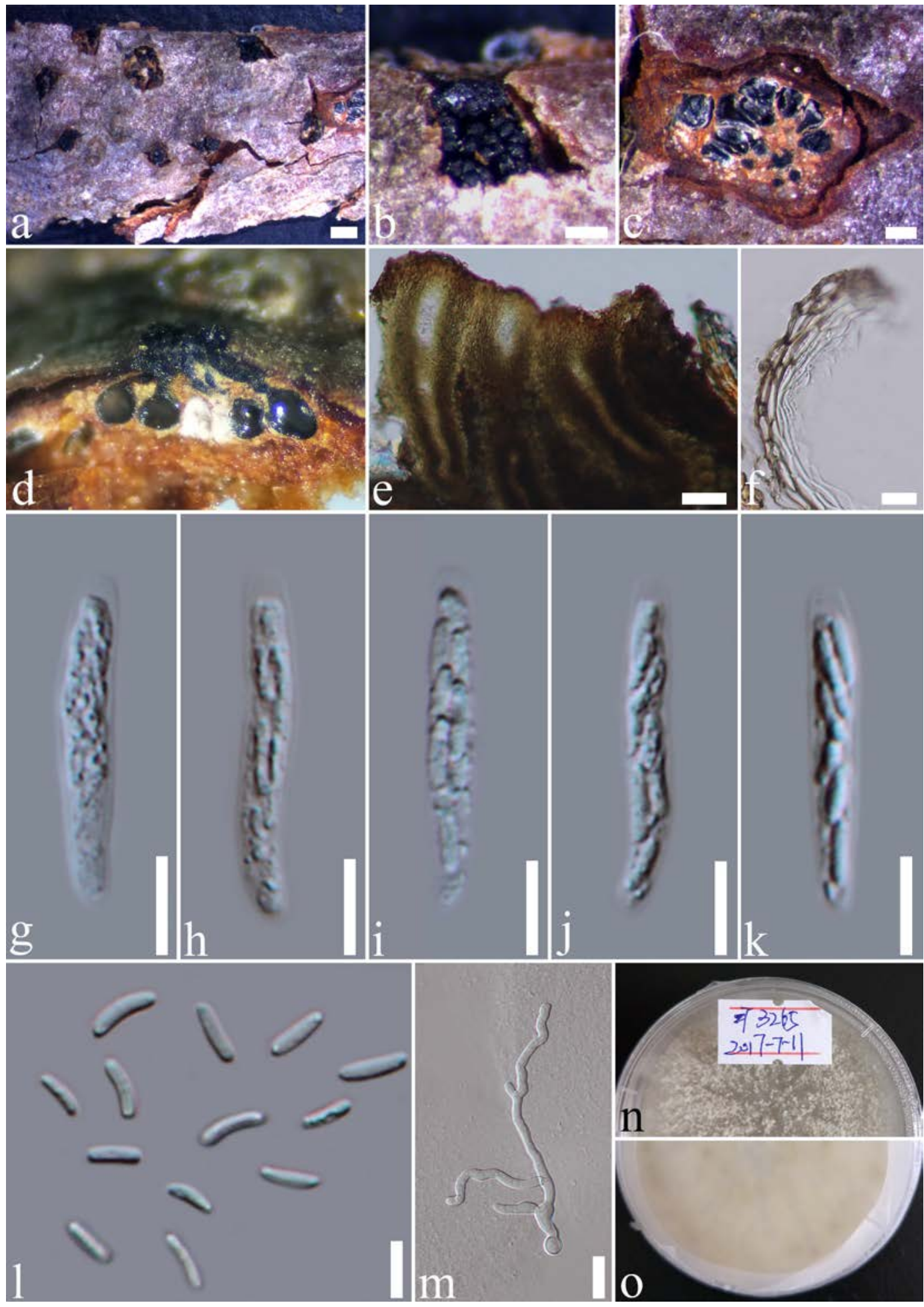

Figure 12 - Cytospora pubescentis (MFLU 17-0727, holotype). a Appearance of stromata on the substrate. b Stroma. c Cross section through stroma. d Vertical section through stroma. e Ostiolar canal. f Peridium. g-k Asci. l Ascospores. m Germinating ascospore. n, o Culture characteristic on PDA after 10 days $(\mathrm{n}=$ colony from above, $\mathrm{o}=$ colony from below). Scale bars: $\mathrm{a}=500 \mu \mathrm{m}, \mathrm{b}, \mathrm{c}=$ $200 \mu \mathrm{m}, \mathrm{e}=50 \mu \mathrm{m}, \mathrm{f}-\mathrm{k}=10 \mu \mathrm{m}, \mathrm{m}=20 \mu \mathrm{m}$. 

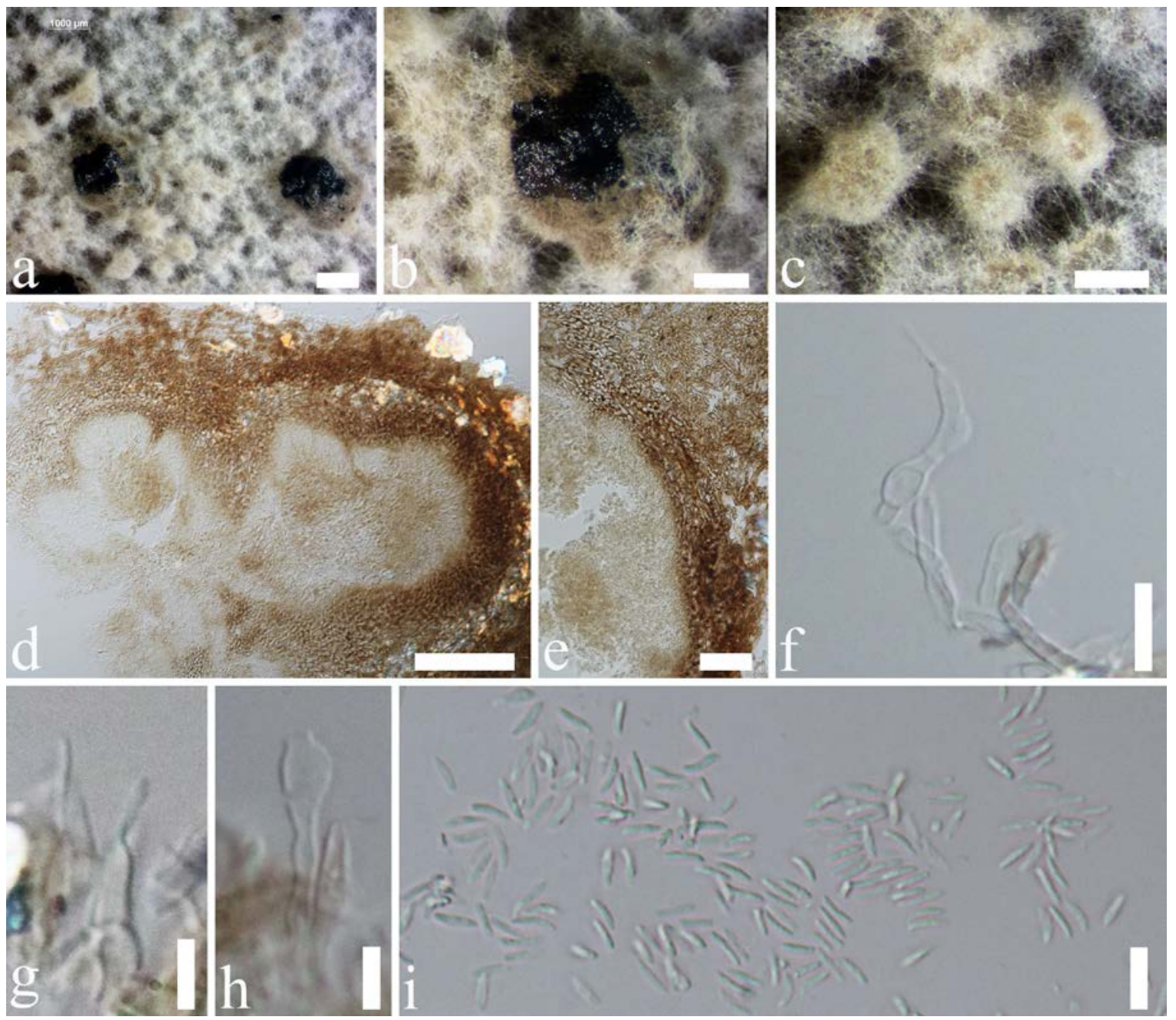

Figure 13 - Cytospora pubescentis (MFLUCC 18-1201, holotype). a Culture surface on PDA. b, c Conidiomata on PDA. d Section of the conidioma. e Peridium. f, g Conidia attached to conidiogenous cells. h Conidiogenous. i Conidia. Scale bars: $\mathrm{a}=1 \mathrm{~mm}, \mathrm{~b}-\mathrm{c}=500 \mu \mathrm{m}, \mathrm{d}=100 \mu \mathrm{m}$, $\mathrm{e}=50 \mu \mathrm{m}, \mathrm{f}, \mathrm{i}=10 \mu \mathrm{m}, \mathrm{g}, \mathrm{h}=5 \mu \mathrm{m}$.

Culture characteristics - Ascospores germinating on PDA within 24 hrs. Germ tubes produced from all sides. Colonies on PDA reaching 5-5.5 cm diam. after 15 days at room temperature, colonies circular to irregular, medium dense, flat or effuse, slightly raised, with edge fimbriate, fluffy to fairy fluffy, white to gray from above, light yellow to brown from below; After 20 days, gray to brown from above, dark brown from below; not producing pigments in agar.

Material examined - Italy, Monte Mirabello, Predappio (Province of Forlì-Cesena [FC]), on a dead land branch of Quercus pubescens, 28 February 2017, E. Camporesi, IT 3265 (MFLU 170727, holotype; KUN-HKAS 100910, isotype), ex-type living culture, MFLUCC 18-1201.

Notes - Cytospora pubescentis can be distinguished from Cytospora quercicola by its smaller asci and ascospores. It differs from Cytospora junipericola by its shorter ascomata, more slender asci and larger ascospores. (Table 2, Senanayake et al. 2017). Cytospora pubescentis differs from Cytospora fraxinigena and Cytospora rosae by having larger asci, ascospores and ostioles (Senanayake et al. 2017). Moreover, the phylogenetic result (Fig. 1) shows that the strain $C$. pubescentis (MFLUCC 18-1201) forms a distinct lineage and shares a sister relationship to $C$. fraxinigena (MFLUCC 14-0868, BBH42442), C. junipericola (MFLUCC 17-0882, BBH42444), C. quercicola (MFLUCC 14-0867, BBH42443) and C. rosae (MFLUCC 14-0845, MFLUCC 171664 ) with moderate support (89\% ML and $86 \% \mathrm{MP})$. Therefore, we identify our specimen as the new taxon $C$. pubescentis and provide the holomorph description for the species. 
Table 2 Synopsis of sexual morph of Cytospora species and related species discussed in this study.

\begin{tabular}{|c|c|c|c|c|c|c|}
\hline Species name & $\begin{array}{c}\text { Stroma length/width } \\
(\mu \mathrm{m})\end{array}$ & $\begin{array}{c}\text { Ascoma } \\
\text { length/width }(\mu \mathrm{m})\end{array}$ & $\begin{array}{l}\text { Ascus length/width } \\
(\mu \mathrm{m})\end{array}$ & $\begin{array}{c}\text { Ascospore } \\
\text { length/width }(\mu \mathrm{m})\end{array}$ & Ostiolar neck $(\mu \mathrm{m})$ & Reference \\
\hline Cytospora ceratosperma & $\begin{array}{l}300-450 \times 500-550 \\
(\bar{X}=300 \times 500)\end{array}$ & - & $\begin{array}{l}(58-) 60-65 \times 10-11(- \\
12)(\bar{X}=63 \times 11)\end{array}$ & $\begin{array}{l}(11-) 12.2-1593.1-4(- \\
4.2)(\bar{x}=14.5 \times 3.7)\end{array}$ & $450-550$ & Tibpromma et al. (2017) \\
\hline $\begin{array}{l}\text { C. cotini (MFLUCC 18- } \\
\text { 1203) }\end{array}$ & 1190-2098 & $\begin{array}{l}\text { (excluding necks) } 183- \\
386 \times 364-613(\bar{X}= \\
284 \times 489)\end{array}$ & $\begin{array}{l}(56-) 61-71(-85) \times \\
(6.5-) 7.5-9.5(-11)(\bar{X} \\
=66 \times 8.4)\end{array}$ & $\begin{array}{l}(10.5-) 12.5-15(-17) \times \\
(2.5-) 3-4(-4.5)(\bar{X}=14 \\
\times 3.5)\end{array}$ & $\begin{array}{l}250-310 \times 120-155 \\
(\bar{X}=276 \times 139)\end{array}$ & This study \\
\hline C. diopuiensis (holotype) & $800-1200$ & $\begin{array}{l}\text { (excluding necks) } 117- \\
192 \times 205-333(\bar{X}= \\
154 \times 269)\end{array}$ & $\begin{array}{l}(23-) 25-31(-34) \times(4- \\
) 4.5-6(-6.5)(\bar{X}=27.8 \\
\times 5.2)\end{array}$ & $\begin{array}{l}(6.5-) 7.5-8.5(-9) \times \\
(1.2-) 1.5-2.5(-3.6)(\bar{X} \\
=8 \times 1.9)\end{array}$ & $\begin{array}{l}242-520 \times 95-121 \\
(\bar{X}=381 \times 108)\end{array}$ & This study \\
\hline $\begin{array}{l}\text { C. fraxinigena } \\
\text { (holotype) }\end{array}$ & - & $\begin{array}{l}350-500 \times 150-230(\bar{X} \\
=429 \times 189)\end{array}$ & $\begin{array}{l}26-33 \times 6.2-7.5(\bar{x}= \\
30 \times 6.7)\end{array}$ & $\begin{array}{l}5.5-7.5 \times 1.5-2(\bar{X}= \\
6.4 \times 1.7)\end{array}$ & $\begin{array}{l}185-200 \times 60-95 \\
(\bar{X}=193 \times 79)\end{array}$ & Senanayake et al. (2017) \\
\hline $\begin{array}{l}\text { C. junipericola } \\
\text { (holotype) }\end{array}$ & - & $630-700 \times 150-250$ & $\begin{array}{l}30-35 \times 5.5-7(\bar{x}=32 \\
\times 6)\end{array}$ & $\begin{array}{l}5-10 \times 1-2(\bar{x}=7 \times \\
1.5)\end{array}$ & $\begin{array}{l}300-500 \times 45-65 \\
(\bar{X}=440 \times 58)\end{array}$ & Senanayake et al. (2017) \\
\hline $\begin{array}{l}\text { C. pingbianensis } \\
\text { (holotype) }\end{array}$ & $880-1524$ & $\begin{array}{l}\text { (excluding necks) } 142- \\
248 \times 113-245(\bar{x}= \\
195 \times 180)\end{array}$ & $\begin{array}{l}(25-) 27-30(-33) \times \\
(3.5-) 4-5(-6)(\bar{X}=28 \\
\times 4.7)\end{array}$ & $\begin{array}{l}(4.6-) 5.8-6.7(-7.5) \times \\
(1-) 1.5-1.9(-2.5)(\bar{X}= \\
6.2 \times 1.7)\end{array}$ & $\begin{array}{l}185-722 \times 27-66 \\
(\bar{X}=453 \times 47)\end{array}$ & This study \\
\hline $\begin{array}{l}\text { C. predappioensis } \\
\text { (holotype) }\end{array}$ & $875-2685$ & $\begin{array}{l}\text { (excluding necks) } 240- \\
480 \times 450-680(\bar{X}= \\
365 \times 567)\end{array}$ & $\begin{array}{l}(25-) 32-42(-54) \times \\
(4.5-) 5.5-8(-9.8)(\bar{X}= \\
37 \times 7.7)\end{array}$ & $\begin{array}{l}(6.5-) 8-10(-11) \times(1- \\
) 1.5-3(-3.5)(\bar{X}=9 \times 2)\end{array}$ & $\begin{array}{l}70-520 \times 100-150 \\
(\bar{X}=444 \times 124)\end{array}$ & Hyde et al. (2018) \\
\hline $\begin{array}{l}\text { C. predappioensis } \\
\text { (MFLUCC 18-1202, } \\
\text { MFLUCC 18-1205) }\end{array}$ & $647-2225$ & $\begin{array}{l}\text { (excluding necks) } 209- \\
413 \times 194-360(\bar{X}= \\
300 \times 277)\end{array}$ & $\begin{array}{l}(23-) 25-38(-50) \times \\
(3.5-) 4-6.5(-8.5)(\bar{x}= \\
32 \times 5.4)\end{array}$ & $\begin{array}{l}(6.5-) 7-10(-12) \times \\
(1.5-) 1.7-3(-3.5)(\bar{X}= \\
8.4 \times 2.2)\end{array}$ & $\begin{array}{l}434-1185 \times 104- \\
145(\bar{X}=725 \times 117)\end{array}$ & This study \\
\hline $\begin{array}{l}\text { C. prunicola (MFLUCC } \\
\text { 18-1200) }\end{array}$ & $622-908$ & $\begin{array}{l}\text { (excluding necks) } 187- \\
270 \times 159-289(\bar{X}= \\
229 \times 224)\end{array}$ & $\begin{array}{l}(45-) 55-68(-78) \times \\
(7.5-) 8.5-10.5(-12) \\
(\bar{X}=62 \times 9.5)\end{array}$ & $\begin{array}{l}(9.5-) 10.5-13.5(-15.5) \\
\times(3-) 3-4.5(-5)(\bar{x}=12 \\
\times 3.7)\end{array}$ & $215-250 \times 57-122$ & This study \\
\hline $\begin{array}{l}\text { C. pubescentis } \\
\text { (MFLUCC 18-1201) }\end{array}$ & $943-1461$ & $\begin{array}{l}\text { (excluding necks) } 183- \\
333 \times 158-259(\bar{X}= \\
258 \times 209)\end{array}$ & $\begin{array}{l}(28-) 32-37(-40) \times(4- \\
) 5-6(-6.8)(\bar{x}=34 \times \\
5.5)\end{array}$ & $\begin{array}{l}(5.7-) 6.8-8.7(-10.3) \times \\
(1.5-) 1.9-2.7(-3.4)(\bar{X} \\
=7.8 \times 2.3)\end{array}$ & $\begin{array}{l}300-460 \times 65-103 \\
(\bar{X}=382 \times 84)\end{array}$ & This study \\
\hline C. quercicola (holotype) & - & $\begin{array}{l}550-725 \times 160-215(\bar{X} \\
=611 \times 190)\end{array}$ & $\begin{array}{l}75-85 \times 15-19(\bar{X}= \\
79 \times 18)\end{array}$ & $\begin{array}{l}16-20 \times 4-6(\bar{x}=17 \times \\
5)\end{array}$ & $\begin{array}{l}285-430 \times 90-130 \\
(\bar{X}=340 \times 101)\end{array}$ & Senanayake et al. (2017) \\
\hline C. rosae (holotype) & - & $\begin{array}{l}235-255 \times 130-150(\bar{X} \\
=240 \times 140)\end{array}$ & $\begin{array}{l}20-23 \times 3.2-3.7(\bar{x}= \\
21 \times 3.7)\end{array}$ & $\begin{array}{l}4.2-6.3 \times 1-1.5(\bar{x}= \\
5.5 \times 1.3)\end{array}$ & $\begin{array}{l}27-140 \times 70-90(\bar{X} \\
=135 \times 87)\end{array}$ & Senanayake et al. 2017 \\
\hline C. sordida (holotype) & - & - & $48-60 \times 8$ & $12 \times 1.5-2$ & - & Nitschke (1870) \\
\hline C. thailandica (holotype) & $400-1000 \times 70-250$ & - & $\begin{array}{l}(21-) 23-25 \times 4.1- \\
4.7(-5)(\bar{X}=22 \times 4.3)\end{array}$ & $\begin{array}{l}(5.6-) 6-6.8 \times 1.3-1.5(- \\
\text { 2) }(\bar{X}=6.6 \times 1.5)\end{array}$ & $70-150$ & $\begin{array}{l}\text { Norphanphoun et al. } \\
\text { (2018) }\end{array}$ \\
\hline
\end{tabular}


Table 3 Synopsis of asexual morph of Cytospora species and related species discussed in this study.

\begin{tabular}{|c|c|c|c|c|}
\hline Species name & $\begin{array}{c}\text { Conidioma } \\
\text { length/width }(\mu \mathrm{m})\end{array}$ & $\begin{array}{l}\text { Conidiogenous cell } \\
\text { length/width }(\mu \mathrm{m})\end{array}$ & Conidium length/width $(\mu \mathrm{m})$ & Reference \\
\hline $\begin{array}{l}\text { Cytospora ampulliformis } \\
\text { (holotype) }\end{array}$ & $680-1200 \times 350-480$ & - & $\begin{array}{l}(5-) 5.6-9 \times 1.3-1.6(-1.7)(\bar{X}=7.5 \times \\
1.6)\end{array}$ & $\begin{array}{l}\text { Norphanphoun et al. } \\
\text { (2017) }\end{array}$ \\
\hline C. coenobitica (holotype) & - & - & $5-6 \times 1$ & Saccardo (1884) \\
\hline C. cotini (holotype) & $800-1000$ & - & $\begin{array}{l}(4.9-) 5.6-6.5 \times 0.8-1.4(-1.7)(\bar{X}=5.9 \\
\times 1.2)\end{array}$ & Hyde et al. (2016) \\
\hline C. galegicola (holotype) & $430-589$ & $\begin{array}{l}(7.2-) 9.5-19.5(-23) \times(1.5-) 1.8-3.2(-4)(\bar{X} \\
=14.4 \times 2.5)\end{array}$ & $\begin{array}{l}(4.8-) 5-6.8(-10.7) \times(0.8-) 1-1.5(-2.0) \\
(\bar{X}=7.6 \times 1.3)\end{array}$ & This study \\
\hline C. gelida (holotype) & $650-1000 \times 350-450$ & - & $\begin{array}{l}(5.3-) 5.7-8 \times 1.4-1.8(-2)(\bar{X}=6.9 \times \\
1.8)\end{array}$ & $\begin{array}{l}\text { Tibpromma et al. } \\
\text { (2017) }\end{array}$ \\
\hline C. gutnerae (holotype) & $800-1500 \times 500-1000$ & - & $8-12.5 \times 3$ & Gvritischvili (1973) \\
\hline C. Iumnitzericola (holotype) & - & $(8-) 8.5-14 \times 0.6-1.4(-1.6)(\bar{X}=8.4 \times 1.4)$ & $(3.7-) 4-4.5 \times 1-1.3(-1.5)(\bar{X}=4 \times 1.2)$ & $\begin{array}{l}\text { Norphanphoun et al. } \\
\text { (2018) }\end{array}$ \\
\hline C. platyclade (holotype) & $\begin{array}{l}(210-) 230-300(-330) \\
\text { (Ectostromatic disc) }\end{array}$ & $5-12 \times 1-1.5$ & $(4-) 4.5-5(-5.5) \times 1-1.5$ & Fan et al. (2020) \\
\hline $\begin{array}{l}\text { C. predappioensis } \\
\text { (MFLUCC 18-1202) }\end{array}$ & $540-665$ & $\begin{array}{l}8.5-10.5(-11) \times(1.4-) 1.5-2.7(-3)(x=9.7 \times \\
2)\end{array}$ & $\begin{array}{l}(4.5-) 5-6.5(-8) \times(0.8-) 1-1.6(-1.8)(\bar{X}= \\
6 \times 1.4)\end{array}$ & This study \\
\hline C. prunicola (holotype) & $500-1000 \times 450-500$ & - & $\begin{array}{l}(4-) 5.2-6.6 \times 1.1-1.3(-1.6)(\bar{X}=5.5 \times \\
1.3)\end{array}$ & Hyde et al. (2018) \\
\hline $\begin{array}{l}\text { C. prunicola (MFLUCC 18- } \\
\text { 1200) }\end{array}$ & $300-588 \times 259-535$ & $\begin{array}{l}(6-) 6.5-11(-13) \times(1-) 1.5-2.5(-3)(\bar{X}=8.7 \\
\times 2)\end{array}$ & $\begin{array}{l}(4-) 5-6.8(-8.2) \times(0.8-) 1-1.5(-2)(\bar{X}=6 \\
\times 1.2)\end{array}$ & This study \\
\hline C. rhodophila (holotype) & - & - & $5-7 \times 1$ & Saccardo (1884) \\
\hline C. rosae & $100-200$ & $10-15 \times 1-1.5(\bar{x}=12 \times 1.2)$ & $3-5 \times 0.5-1(\bar{x}=2 \times 1)$ & Senanayake et al. 2017 \\
\hline C. subclypeata & $500-750$ & $25 \times 1$ & $4-5 \times 1$ & Saccardo (1896) \\
\hline C. terebinthi (holotype) & $500-667$ & - & $6-7 \times 1-1.5$ & Bresadola (1892) \\
\hline
\end{tabular}


Table 4 Nucleotide differences of Cytospora species and related species discussed in this study.

\begin{tabular}{|c|c|c|c|c|c|c|c|}
\hline \multirow{2}{*}{ New Taxa } & \multirow{2}{*}{ Strains } & \multirow{2}{*}{ Taxa compared with } & \multicolumn{4}{|c|}{ Fragment length, Gap, Identities (\%), Query cover (\%), Difference (\%) } & \multirow{2}{*}{ References } \\
\hline & & & ITS & LSU & ACT & RPB2 & \\
\hline \multirow[t]{2}{*}{ Cytospora cedri } & MFLUCC 18-1219a & $\begin{array}{l}\text { Cytospora cedri } \\
\text { (CBS 196.50) }\end{array}$ & $542,0,99.81,97,0.19$ & - & - & - & $\begin{array}{l}\text { Adams et al. } \\
\text { (2002) }\end{array}$ \\
\hline & MFLUCC 18-1219b & $\begin{array}{l}\text { C. cedri } \\
\text { (CBS 196.50) }\end{array}$ & $551,0,100,94,0$ & - & - & - & $\begin{array}{l}\text { Adams et al. } \\
\text { (2003) }\end{array}$ \\
\hline \multirow[t]{4}{*}{ C. cotini } & \multirow[t]{4}{*}{ MFLUCC 18-1203 } & $\begin{array}{l}\text { C. cotini } \\
\left(\text { MFLUCC 14-1050 }{ }^{\mathrm{T}} \text { ) }\right.\end{array}$ & $557,0,99.61,92,0.39$ & $811,0,100,100,0$ & - & $\begin{array}{l}784,0,100,100, \\
0\end{array}$ & $\begin{array}{l}\text { Norphanphoun } \\
\text { et al. (2017) }\end{array}$ \\
\hline & & $\begin{array}{l}\text { C. ampulliformis } \\
\left(\text { MFLUCC 16-0583 }{ }^{\mathrm{T}} \text { ) }\right.\end{array}$ & $557,0,99.60,90,0.4$ & $811,2,99.3,100,0.7$ & $\begin{array}{l}235,0,99.55,94, \\
0.45\end{array}$ & $\begin{array}{l}784,0,99.73,94, \\
0.27\end{array}$ & $\begin{array}{l}\text { Norphanphoun } \\
\text { et al. (2017) }\end{array}$ \\
\hline & & $\begin{array}{l}\text { C. ceratosperma } \\
\text { (MFLUCC 16-0625) }\end{array}$ & $577,1,99.80,89,0.2$ & $811,2,98.8,100,1.2$ & $\begin{array}{l}235,3,97.7,86.9, \\
2.3\end{array}$ & $\begin{array}{l}\text { 784, 0, 99.06, 94, } \\
0.94\end{array}$ & $\begin{array}{l}\text { Tibpromma et } \\
\text { al. (2017) }\end{array}$ \\
\hline & & $\begin{array}{l}\text { C. gelida } \\
\left(\text { MFLUCC 16-0634 }{ }^{\mathrm{T}} \text { ) }\right.\end{array}$ & $557,0,98.62,91,1.38$ & $811,2,98.6,99.4,1.4$ & $\begin{array}{l}235,1,98.6,86.6, \\
1.4\end{array}$ & $784,0,100,94,0$ & $\begin{array}{l}\text { Tibpromma et } \\
\text { al. (2017) }\end{array}$ \\
\hline C. diopuiensis & MFLUCC 18-1419 & $\begin{array}{l}\text { C. diopuiensis } \\
\text { (GJJM16) }\end{array}$ & $530,0,99.22,96,0.78$ & - & - & - & $\begin{array}{l}\text { Jayanthi et al. } \\
\text { (2018) }\end{array}$ \\
\hline \multirow[t]{2}{*}{ C. predappioensis } & MFLUCC 18-1202 & $\begin{array}{l}\text { C. predappioensis } \\
\left(\text { MFLUCC } 17-2458^{\mathrm{T}} \text { ) }\right.\end{array}$ & $533,2,99.81,95,0.19$ & $650,0,99.7,100,0.19$ & $174,0,98,78.4,2$ & - & $\begin{array}{l}\text { Hyde et al. } \\
\text { (2018) }\end{array}$ \\
\hline & MFLUCC 18-1205 & $\begin{array}{l}\text { C. predappioensis } \\
\left(\text { MFLUCC } 17-2458^{\mathrm{T}} \text { ) }\right.\end{array}$ & $586,0,99.3,95,0.7$ & $650,0,100,100,0$ & $173,0,96,78.6,4$ & - & $\begin{array}{l}\text { Hyde et al. } \\
\text { (2018) }\end{array}$ \\
\hline
\end{tabular}

\section{Acknowledgements}

This study is supported by the Joint Fund of the National Natural Science Foundation of China and the Karst Science Research Center of Guizhou province (Grant No. U1812401). Kevin D. Hyde thanks to the Mushroom Research Foundation and Thailand Research Fund (TRF: RDG613000) entitled "Impact of climate change on fungal diversity and biogeography in the Greater Mekong Subregion for supporting this research. We would like to thank Shaun Pennycook (Landcare Research Manaaki Whenua, New Zealand) for advising on the fungal names. Qiu-Ju Shang would like to thank Florent P. Trouillas and Dan-Feng Bao for their kind support on manuscript writing. 


\section{References}

Ariyawansa HA, Hyde KD, Jayasiri SC, Buyck B et al. 2015 - Fungal diversity notes 111-252 taxonomic and phylogenetic contributions to fungal taxa. Fungal Diversity 75, 27-274.

Adams GC, Roux J, Wingfield MJ. 2006 - Cytospora species (Ascomycota, Diaporthales, Valsaceae): introduced and native pathogens of trees in South Africa. Australasian Plant Pathology 35, 521-548.

Adams GC, Surve-Iyer RS, Iezzoni A. 2002 - Ribosomal DNA sequence divergence and group I introns within Leucostoma species, L. cinctum, L. persoonii, and L. parapersoonii sp. nov., ascomycetes that cause Cytospora canker of fruit trees. Mycologia 94, 947-967.

Adams GC, Wingfield MJ, Common R, Roux J. 2005 - Phylogenetic relationships and morphology of Cytospora species and related teleomorphs (Ascomycota, Diaporthales, Valsaceae) from Eucalyptus. Studies in Mycology 52, 1-144.

Bills GF. 1996 - Isolation and Analysis of Endophytic Fungal Communities from Woody Plants. St Paul, MN: American Phytopathological Society Press.

Barr ME. 1978 - The Diaporthales in North America with emphasis on Gnomonia and its segregates. Mycologia Memoir 7, 1-232.

Barr ME. 1990 - Prodomus to nonlichenized, pyrenomycetous members of the class Hymenoascomycetes. Mycotaxan 39, 43-184.

Bresadola G. 1892 - Fungi tridentini. 2, 44.

Bulgakov TS. 2010 - Microfungi of Leucostoma and Valsa genera and their Cytospora anamorphs on arboreal plants in the steppe zone of Southern Russia. Actual problems of ecology: Mater. IV All-Russian Science Conference in Vladikavkaz, North Ossetian State University. 40-45 (in Russian).

Carbone I, Kohn LM. 1999 - A method for designing primer sets for speciation studies in fiamentous ascomycetes. Mycologia 91, 553-556.

Castlebury LA, Rossman AY, Jaklitsch WJ, Vasilyeva LN. 2002 - A preliminary overview of Diaporthales based on large subunit nuclear ribosomal DNA sequences. Mycologia 94, 10171031.

Chomnunti P, Hongsanan S, Aguirre-Hudson B, Tian Q et al. 2014 - The sooty moulds. Fungal Diversity 66, 1-36.

Christensen CM. 1940 - Studies on the biology of Valsa sordida and Cytospora chrysosperma. Phytopathology 30, 459-475.

Crous PW, Schumacher RK, Akulov A, Thangavel R et al. 2019 - New and Interestig Fungi. 2. Fungal Systematics and Evolution 3, 57-134.

Crous PW, Wingfield MJ, Guarro J, Cheewangkoon R et al. 2013 - Fungal Planet description sheets: 154-213. Persoonia 31, 188-296.

Dai DQ, Phookamsak R, Wijayawardene NN, Li WJ et al. 2017 - Bambusicolous fungi. Fungal Diversity 82, 1-105.

Défago G. 1942 - Seconde contributioń a le connaissance des Valsèés v.H. Phytopathologische Zeitschrift 14, 103-147.

Du Q, Zhao SF, Wu CL, Kong L et al. 2013 - Root rot of Chinese jujube (Ziziphus jujuba) caused by Cytospora sacculus in China. Plant Disease 97, 1661.

Ehrenberg CG. 1818 - Sylvae Mycologicae Berolinenses. Formis Theophili Bruschcke, Berlin, Germany. [In Latin]

Fan XL, Bezerra JDP, Tian CM, Crous PW. 2020 - Cytospora (Diaporthales) in China. Persoonia $45,1-45$.

Fan XL, Hyde KD, Liu M, Liang YM et al. 2015a - Cytospora species associated with walnut canker disease in China, with description of a new species C. gigalocus. Fungal Biology 119, 310-319.

Fan XL, Hyde KD, Yang Q, Liang YM et al. 2015b - Cytospora species associated with canker disease of three anti-desertification plants in northwestern China. Phytotaxa 197, 227-244. 
Fan XL, Liang YM, Ma R, Tian CM. 2014a - Morphological and phylogenetic studies of Cytospora (Valsaceae, Diaporthales) isolates from Chinese scholar tree, with description of a new species. Mycoscience 55, 252-259.

Fan XL, Tian CM, Yang Q, Liang YM et al. 2014b - Cytospora from Salix in northern China. Mycotaxon 129, 303-315.

Fotouhifar KB, Hedjaroude GA, Leuchtmann A. 2010 - ITS rDNA phylogeny of Iranian strains of Cytospora and associated teleomorphs. Mycologia 102, 1369-1382.

Fries EM. 1823 - Systema mycologicum vol 2, Greifswald, Germany. [in Latin]

Gvritischvili MN. 1973 - Mikologiya i Fitopatologiya 7, 35.

Gvritishvili MN. 1982 - The fungal genus Cytospora in the USSR. Izdatelstve Sabchota Sakarstvelo, Tbilici, Russia.

Hall T. 1999 - BioEdit: a user-friendly biological sequence alignment editor and analysis program for windows 95/98/NT. Nucleic Acids Symposium Series 41, 95-98.

Hillis DM, Bull JJ. 1993 - An empirical test of bootstrapping as a method for assessing confidence in phylogenetic analysis. Systematic Biology 42, 182.

Hubbes M. 1960 - Untersuchungen uber die Valsaceengattung Valseutypella v. H. Phytopathologische Zeitschrift 39, 389-400.

Hyde KD, Chaiwan N, Norphanphoun C, Boonmee S et al. 2018 - Mycosphere notes 169-224. Mycosphere 9, 271-430.

Hyde KD, Norphanphoun C, Abreu VP, Bazzicalupo A et al. 2017 - Fungal diversity notes 603708: taxonomic and phylogenetic notes on genera and species. Fungal Diversity. 87, 1-235.

Hyde KD, Hongsanan S, Jeewon R, Bhat DJ et al. 2016 - Fungal diversity notes 367-490: taxonomic and phylogenetic contributions to fungal taxa. Fungal Diversity 80, 1-270.

Index Fungorum. 2019 - http://www.indexfungorum.org/Names/Names.asp?pg=4

Jami F, Marincowitz S, Crous PW, Jacobsohn A et al. 2018 - A new Cytospora species pathogenic on Carpobrotus edulis in its natie habitat. Fungal Systematis and Evolutin 2, 37-43.

Jayanthi G, Arun babu R, Ramachandran R, Karthikeyan K et al. 2018 - Production, isolation and structural elucidation of a novel antimicrobial metabolite from the endophytic fungus, Phomopsis/Diaporthe theae. International Journal of Pharmacy and Biological Sciences 8, 2321-3272.

Jayasiri SC, Hyde KD, Ariyawansa HA, Bhat DJ et al. 2015 - The Faces of Fungi database: fungal names linked with morphology, phylogeny and human impacts. Fungal Diversity 74, 3-18.

Jeewon R, Hyde KD. 2016 - Establishing species boundaries and new taxa among fungi: recommendations to resolve taxonomic ambiguities. Mycosphere 7, 1669-1677.

Katoh K, Standley DM. 2013 - MAFFT Multiple Sequence Alignment Software Version 7: Improvements in Performance and Usability. Molecular Biology and Evolution 30, 772-780.

Kirk PM, Cannon PF, Minter DW, Stalpers JA. 2008 - Ainsworth \& Bisby's dictionary of the fungi, 10th edn. CABI, Wallingford.

Kishino H, Hasegawa M. 1989 - Evaluation of the maximum likelihood estimate of the evolutionary tree topologies from DNA sequence data, and the branching order in Hominoidea. Journal of Molecular Evolution 29, 170-179.

Kobayashi T. 1970 - Taxonomic studies of Japanese Diaporthaceae with special reference to their life-histories. Tokyo, Japan.

Lawrence DP, Travadon R, Pouzoulet J, Rolshausen PE et al. 2017 - Characterization of Cytospora isolates from wood cankers of declining grapevine in North America, with the descriptions of two new Cytospora species. Plant Pathology 5, 713-725.

Lawrence DP, Holland LA, Nouri MT, Travadon R et al. 2018 - Molecular phylogeny of Cytospora species associated with canker diseases of fruit and nut crops in California, with the descriptions of ten new species and one new combination. IMA Fungus 9, 333-370.

Li GJ, Hyde KD, Zhao RN, Hongsanan S et al. 2016 - Fungal divers notes 253-366: taxonomic and phylogenetic contributions to fungal taxa. Fungal Divers 78, 1-237. 
Liu JK, Chomnunti P, Cai L, Phookamsak R et al. 2010 - Phylogeny and morphology of Neodeightonia palmicola sp. nov. from palms. Sydowia 62, 261-276.

Liu JK, Hyde KD, Jones EBG, Ariyawansa HA et al. 2015 - Fungal Diversity Notes 1-100: Taxonomic and phylogenetic contributions to fungal species. Fungal Diversity 72, 1-197.

Liu YJ, Whelen S, Hall BD. 1999 - Phylogenetic relationships among ascomycetes: evidence from an RNA polymerase II subunit. Molecular Biology and Evolution 16, 1799-1808.

Maharachchikumbura SSN, Hyde KD, Jones EBG, McKenzie EHC et al. 2016 - Families of Sordariomycetes. Fungal Diversity 79, 1-317.

Maharachchikumbura SSN, Hyde KD, Jones EBG, McKenzie EHC et al. 2015 - Towards a natural classification and backbone tree for Sordariomycetes. Fungal Diversity 72, 199-301.

McNeill J, Barrie FR, Buck WR, Demoulin V et al. 2012 - International code of nomenclature for Algae, Fungi, and Plants (Melbourne Code) 154.

Miller MA, Pfeiffer W, Schwartz T. 2010 - Creating the CIPRES Science Gateway for inference of large phylogenetic trees. In Gateway Computing Environments Workshop (GCE), 1-8. Ieee.

NCBI. 2019 - National Center for Biotechnology Information [Internet]. Bethesda (MD): National Library of Medicine (US), National Center for Biotechnology Information; [1988] - [cited September 2019]. Available from: https://www.ncbi.nlm.nih.gov/

Nitschke T. 1870 - Diaporthe. Pyrenomycetes Germanici. 2, 161-320.

Norphanphoun C, Doilom M, Daranagama DA, Phookamsak R et al. 2017 - Revisiting the genus Cytospora and allied species. Mycosphere 8, 51-97.

Norphanphoun C, Raspé O, Jeewon R, Wen TC et al. 2018 - Morphological and phylogenetic characterisation of novel Cytospora species associated with mangroves. MycoKeys 38, 93120.

Nylander JAA. 2008 - MrModeltest2 v. 2.3 (Program for selecting DNA substitution models using PAUP*). Evolutionary Biology Centre, Uppsala, Sweden. Rambaut, A. (2012) FigTree, version 1.4.2. University of Edinburgh, Edinburgh.

Palavouzis SC, Tzamos S, Paplomatas E, Thomidis T. 2015 - First report of Cytospora punicae isolated from pomegranate plants with symptom of collar rot in northern Greece. Journal of Plant Pathology 97, 209-220.

Pan M, Zhu HY, Tian CM, Alvarez LV et al. 2018 - Cytospora piceae sp. nov. associated with canker disease of Picea crassifolia in China. Phytotaxa 383, 181-196.

Petch T. 1925 - Additions to Ceylon fungi. III. Annals of the Royal Botanic Gardens Peradeniya 9, 313-328.

Phookamsak R, Hyde KD, Jeewon R, Wanasinghe DN et al. 2019 - Fungal diversity notes 9291035: taxonomic and phylogenetic contributions on genera and species of fungi. Fungal Diversity 95, 1-273.

Rambaut A. 2012 - FigTree, version 1.4. 2. University of Edinburgh, Edinburgh.

Rannala B, Yang Z. 1996 - Probability distribution of molecular evolutionary trees: a new method of phylogenetic inference. Journal of Molecular Evolution 43, 304-311.

Rossman AY, Adams GC, Cannon PF, Castlebury LA et al. 2015 - Recommendations of generic names in Diaporthales competing for protection or use. IMA Fungus 6, 145-154.

Saccardo PA. 1884 - Sylloge Fungorum vol 3. Typis Seminarii, Italy. [in Latin]

Saccardo PA. 1896 - Malpighia 10, 273.

Senanayake IC, Crous PW, Groenewald JZ, Maharachchikumbura SSN et al. 2017 - Families of Diaporthales based on morphological and phylogenetic evidence. Studies in Mycology 86, 217-296.

Silvestro D, Michalak I. 2012 - raxmlGUI: a graphical front-end for RAxML. Organisms Diversity and Evolution 12, 335-337.

Spielman LJ. 1983 - Taxonomy and Biology of Valsa Species on Hardwoods in North America, with Special Reference to Species on Maples. Cornell University, NY, USA.

Spielman LJ. 1985 - A monograph of Valsa on hardwoods in North America. Canadian Journal of Botany 63, 1355-1378. 
Swofford DL. 2002 - PAUP*: phylogenetic analysis using parsimony (and other methods), version 4. Sunderland, MA: Sinauer

Sydow H, Sydow P, Butler EJ. 1916 - Fungi Indiae orientalis pars V. Annales Mycologici 14, 177220.

Tibpromma S, Hyde KD, Jeewon R, Maharachchikumbura SSN et al. 2017 - Fungal diversity notes 491-602: taxonomic and phylogenetic contributions to fungal taxa. Fungal Diversity 83, 1261.

Vasilyeva LN. 1988 - A new treatment of the family Valsaceae. Systema Axcomycetum 7, 13-21.

Vasilyeva LN. 1994 - 'Pyrenomycetes of the Russian Far East, 2. Valsaceae.' (Institute of Biology and Pedology, Far East Branch of the Russian Academy of Sciences: Vladivostok, Russia)

Vilgalys R, Hester M. 1990 - Rapid genetic identification and mapping of enzymatically amplified ribosomal DNA from several Cryptococcus species. Journal of Bacteriology 172, 4238-4246.

Urban Z. 1957 - Vorlaufige Mitteilung der Ergebnisse einer Revision der Gattungen Valsa and Valsella. Prestia 29, 394-395.

von Höhnel F. 1906 - Fragmente zur Mykologie 73. Über valsa melanodiscus Otth. Stizungberichte der kaiserlichen Akademie der Wisenschaften zu Wein, Mathematisch-Naturwissenschaftliche Klasse, Abteilung 1, 84-86.

von Höhnel F. 1914 - Fragmente zur Mykologie 863. Über Dendrophoma pruinosa (Fr.) Sacc. Sitzungsberichte der Kaiserlichen Akademie der Wissenschaften zu Wien, MathematischNaturwissenschaftliche Klasse, Abteilung 1, 84-86.

von Höhnel F. 1917 - System der Diaportheen. Berichte der Deutschen Botanischen Gesellschaft 35, 631-638.

von Höhnel F. 1919 - Zu meinem System der Diaportheen. Annales Mycologici 17, 131.

von Höhnel F. 1928 - Über Cytospora melanodiscus (Otth.) Hohn. Mitteilungen aus dem Botanischen Laboratorium der Technischen Hochschule in Wien 5, 16-18.

von Petrak F. 1919 - Mycologische Notize. I. Annales Mycologici 17, 59-100.

von Petrak F. 1969 - Ergebnisse einer Revision der Grundtypen verschiedener Gattungen der Ascomyceten und Fungi imperfecti. Sydowia 23, 265-272.

Wang XL, Wei JL, Huang LL, Kang ZS. 2011 - Re-evaluation of pathogens causing Valsa canker on apple in China. Mycologia 103, 317-324.

Wang YL, Lu Q, Decock C, Li YX et al. 2015 - Cytospora species from Populus and Salix in China with C. davidiana sp. nov.. Fungal Biology 119, 420-432.

White TJ, Bruns T, Lee S, Taylor J. 1990 - Amplification and direct sequencing of fungal ribosomal RNA genes for phylogenetics. PCR protocols: a guide to methods and applications 18, 315-322.

Yang Q, Fan ZL, Crous PW, Liang YM et al. 2015 - Cytospora from Ulmus pumila in Northern China. Mycological Progress 14, 74.

Zhang QT, He M, Lu Q, Liang J et al. 2013 - Morphological and molecular identification of Cytospora germanica causing canker on Populus spp. in China. Plant Disease 97, 846-846.

Zhang QT, Lu Q, He M, Decock C et al. 2014 - Cytospora palm sp. nov. (Diaporthales, Ascomycota), a canker agent on Cotinus coggygria (Anacardiaceae) in Northern China. Cryptogamie Mycologie 35, 211-220.

Zhaxybayeva O, Gogarten JP. 2002 - Bootstrap, Bayesian probability and maximum likelihood mapping: exploring new tools for comparative genome analyses. Genomics 3, 1-15.

Zhu HY, Tian CM, Fan XL. 2018 - Multigene phylogeny and morphology reveal Cytospora spiraeae sp. nov. (Diaporthales, Ascomycota) in China. Phytotaxa 338, 049-062. 